\title{
Emissions of isoprenoids and oxygenated biogenic volatile organic compounds from a New England mixed forest
}

\author{
K. A. McKinney ${ }^{1}$, B. H. Lee ${ }^{2}$, A. Vasta ${ }^{1}$, T. V. Pho ${ }^{1, *}$, and J. W. Munger ${ }^{2}$ \\ ${ }^{1}$ Department of Chemistry, Amherst College, Amherst, Massachusetts, USA \\ ${ }^{2}$ Department of Earth and Planetary Sciences and School of Engineering and Applied Sciences, Harvard University, \\ Cambridge, Massachusetts, USA \\ *now at: Department of Chemistry and Biochemistry, University of California, Santa Barbara, California, USA
}

Received: 29 September 2010 - Published in Atmos. Chem. Phys. Discuss.: 22 November 2010

Revised: 31 March 2011 - Accepted: 12 April 2011 - Published: 24 May 2011

\begin{abstract}
Fluxes of biogenic volatile organic compounds, including isoprene, monoterpenes, and oxygenated VOCs measured above a mixed forest canopy in central Massachusetts during the 2005 and 2007 growing seasons are reported. Mixing ratios were measured using proton transfer reaction mass spectrometry (PTR-MS) and fluxes computed by the disjunct eddy covariance technique. Isoprene was by far the predominant BVOC emitted at this site, with summer mid-day average fluxes of 5.3 and $4.4 \mathrm{mg} \mathrm{m}^{-2} \mathrm{hr}^{-1}$ in 2005 and 2007, respectively. In comparison, mid-day average fluxes of monoterpenes were 0.21 and $0.15 \mathrm{mg} \mathrm{m}^{-2} \mathrm{hr}^{-1}$ in each of these years. On short times scales (days), the diel pattern in emission rate compared well with a standard emission algorithm for isoprene. The general shape of the seasonal cycle and the observed decrease in isoprene emission rate in early September was, however, not well captured by the model. Monoterpene emission rates exhibited dependence on light as well as temperature, as determined from the improved fit to the observations obtained by including a light-dependent term in the model. The mid-day average flux of methanol from the canopy was $0.14 \mathrm{mg} \mathrm{m}^{-2} \mathrm{hr}^{-1}$ in 2005 and $0.19 \mathrm{mg} \mathrm{m}^{-2} \mathrm{hr}^{-1}$ in 2007 , but the maximum flux was observed in spring (29 May 2007), when the flux reached $1.0 \mathrm{mg} \mathrm{m}^{-2} \mathrm{hr}^{-1}$. This observation is consistent with enhanced methanol production during leaf expansion. Summer mid-day fluxes of acetone were $0.15 \mathrm{mg} \mathrm{m}^{-2} \mathrm{hr}^{-1}$ during a short period in 2005, but only $0.03 \mathrm{mg} \mathrm{m}^{-2} \mathrm{hr}^{-1}$ averaged over 2007. Episodes of negative fluxes of oxygenated
\end{abstract}

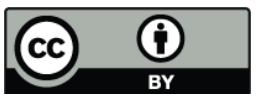

Correspondence to: K. A. McKinney (kamckinney@amherst.edu)
VOCs, particularly acetone, were observed periodically, especially in 2007. Thus, deposition within the canopy could help explain the low season-averaged flux of acetone in 2007. Fluxes of species of biogenic origin at mass-to-charge $(\mathrm{m} / \mathrm{z})$ ratios of $73\left(0.05 \mathrm{mg} \mathrm{m}^{-2} \mathrm{hr}^{-1}\right.$ in $2005 ; 0.03 \mathrm{mg} \mathrm{m}^{-2} \mathrm{hr}^{-1}$ in 2007) and $153\left(5 \mu \mathrm{g} \mathrm{m}^{-2} \mathrm{hr}^{-1}\right.$ in 2007), possibly corresponding to methyl ethyl ketone and an oxygenated terpene or methyl salicylate, respectively, were also observed.

\section{Introduction}

Volatile organic compounds (VOCs) play a critical role in maintaining the oxidant balance of the lower atmosphere, acting as either a source or sink of oxidants, depending on the local photochemical conditions. In the presence of $\mathrm{NO}_{\mathrm{x}}$, VOC oxidation can enhance ozone levels, contributing to poor air quality, and form peroxyacyl nitrates (PANs), resulting in the transport of $\mathrm{NO}_{\mathrm{x}}$ to remote areas (Atkinson, 2000). At the same time, oxidation of VOCs can yield reaction products with reduced vapor pressures, which then condense to form secondary organic aerosol (SOA), giving rise to negative health effects and impacts on cloud formation and the atmospheric radiative balance. Although these processes occur for VOCs of both anthropogenic and biogenic origin, several factors contribute to making biogenic volatile organic compounds (BVOCs) the dominant contributors to VOC chemistry throughout most of the troposphere (Fehsenfeld et al., 1992; Chameides et al., 1988). With a total source strength of ca. $1150 \mathrm{Tg} \mathrm{C} \mathrm{yr}^{-1}$, global emissions of BVOCs outweigh those of anthropogenic VOCs by a factor of 10 (Guenther et al., 1995). Biogenic compounds also tend

Published by Copernicus Publications on behalf of the European Geosciences Union. 
to be more reactive than their anthropogenic counterparts and to more readily form SOA (Atkinson and Arey, 1998; Griffin et al., 1999; Kanakidou et al., 2005; Kavouras et al., 1998; Helmig et al., 2006). Hence, a comprehensive understanding of the processes regulating BVOC concentrations is of fundamental importance in modeling the chemistry of the troposphere and predicting its response to global environmental change (Kulmala et al., 2004; Lathiere et al., 2006; Peñuelas and Llusia, 2003; Peñuelas and Staudt, 2010).

The major classes of BVOCs (and their relative contributions to the total budget) are the isoprenoids, consisting of isoprene (35-45\%), monoterpenes (11-25\%), sesquiterpenes and functionalized terpenes (minor), oxygenated VOCs $(20-30 \%)$, and other hydrocarbons $(<10 \%)$ (Guenther et al., 1995, 2000). Together, fluxes of these compounds can represent reemission of a few percent of the photosynthetically fixed carbon (Guenther, 2002; Kesselmeier et al., 2002). The physiological purposes served by these compounds vary greatly with chemical species, ranging from protection against high temperatures or oxidative stress, to plant signaling, to regulation of metabolism, and many are as yet not well understood (Sharkey et al., 2008; Kesselmeier and Staudt, 1999; Fall, 2003). This variety is reflected in the dependence of emission rates on a number of physicochemical, physiological and environmental factors, including radiation, temperature, phenology, water and nutrient availability, enzyme activity, plant species and physical structure, solubility and vapor pressure (Kesselmeier and Staudt, 1999; Niinemets et al., 2004; Laothawornkitkul et al., 2009).

Emission models attempt to capture the most important of these dependencies, using data from leaf- and canopyscale measurements of emissions under controlled and ambient conditions to formulate functions describing observed emissions patterns. Among emission models, those for isoprene and monoterpenes are the most robust and well characterized, though shortcomings do exist (Guenther et al., 1993, 2006; Grote and Niinemets, 2008; Keenan et al., 2009). This is in part due to the fact that the mechanisms governing the emissions of these compounds are relatively straightforward. Both have sufficiently high vapor pressures that they respond rapidly to changes in environmental conditions such as light and temperature, with minimal mediation by the plant (Guenther et al., 1993; Niinemets et al., 2004). In contrast, the oxygenated BVOCs are more polar, hence more soluble, exhibit lower vapor pressures over water, and are more affected by plant processes such as transpiration and stomatal opening (Fall, 2003; Seco et al., 2007). Hence, more complex models are needed to describe their behavior (Niinemets and Reichstein, 2003a, b). There is also less available data on the oxygenated BVOCs with which to constrain model mechanisms (Seco et al., 2007). As a result, emissions models for the oxygenated species are less well developed, and no standard canopy-scale formulations have yet been adopted.

Uncertainties in the existing data on emissions of BVOCs and their dependence on environmental factors make predic- tions of future emission trends and the response to changing climate difficult (Grote and Niinemets, 2008; Keenan et al., 2009). Canopy-scale studies, which can bridge the divide between leaf-level experiments and global models and be used to test the accuracy of model parameterizations, are a critical component in improving model formulations. Although there have been studies of BVOC emissions from forested sites in the Midwestern, western, and southeastern US, as well as other sites worldwide, there are relatively few data from the Northeast (Goldstein et al., 1998), and very few long-term records of emission rates exist anywhere (Pressley et al., 2005). More are needed to help fill these gaps and to assess the factors influencing variability of emissions over interannual and decadal time scales.

In addition to the common major BVOC species, recent studies have suggested that a wide range of unidentified BVOCs are emitted from forests and can contribute significantly to the oxidant budget and SOA formation (Goldstein and Galbally, 2007). The evidence includes observations of oxidant concentrations and $\mathrm{OH}$ reactivity that imply more active VOC chemistry than expected based on known emission rates (Goldstein et al., 2004; Faloona et al., 2001; Di Carlo et al., 2004) and direct measurements of previously undetected, sometimes highly reactive, species in forest air (Holzinger et al., 2005; Kim et al., 2010; Ciccioli et al., 1999). Due to their reactivity, these compounds may contribute disproportionately to aerosol growth, despite their relatively small abundances (Ng et al., 2006; Bonn and Moortgat, 2003). If emitted, some of these compounds may not escape the forest canopy (Ciccioli et al., 1999), but others may have lifetimes long enough that they have measureable canopy-scale fluxes. Direct detection of the fluxes of novel species out of forest canopies are required to assess their importance in local and regional photochemistry and aerosol growth.

In this study, we report emission rates of isoprenoids and oxygenated VOCs from a New England mixed forest over two growing seasons determined by applying the disjunct eddy covariance method to PTR-MS measurements. In addition to the major BVOCs such as isoprene, monoterpenes, methanol, and acetone, several less-studied species, tentatively identified as methyl ethyl ketone and oxygenated terpenes (or isomers), are also observed. The results are used to analyze the most dominant factors determining emission rates over the course of a growing season, to test the ability of standard emission algorithms to predict daily and seasonal variations, and to determine standardized emission rates suitable for comparison with studies performed under differing conditions and for inclusion in model emission inventories. They also represent the establishment of a longer-term data record that will provide information on seasonal to interannual patterns in emission for which there is less existing data. 


\section{Methods}

\subsection{Site description}

Field studies were carried out at the Environmental Measurement Site (EMS) at Harvard Forest in Petersham, MA $\left(42.54^{\circ} \mathrm{N}, 72.17^{\circ} \mathrm{W}\right.$, elevation $\left.340 \mathrm{~m}\right)$. The forest is located in a rural area in central Massachusetts but is influenced by the east-coast urban corridor (New York City, coastal Connecticut, and the Connecticut River valley) 50 to $200 \mathrm{~km}$ to the southwest as well as regional-scale transport from the Midwest and Mid-Atlantic States. Typical mean summertime mid-day ozone and NOy mixing ratios at the site are $58 \pm 19 \mathrm{ppbv}$ and $5.1 \pm 2.7 \mathrm{ppbv}$, respectively, for periods of SW winds and $40 \pm 12 \mathrm{ppbv}$ and $2.3 \pm 1.4 \mathrm{ppbv}$ for periods of NW winds (Munger et al., 1996; Moody et al., 1998).

The forest stand is $75-110$ years old and is composed of red oak (36\% of biomass), red maple (22\%), red pine ( $8 \%$ ), hemlock (13\%), birch (5\%), white pine $(6 \%)$, cherry (3\%), spruce $(2 \%)$ and beech $(0.8 \%)$ (Urbanski et al., 2007). This distribution is updated from that reported by Goldstein et al. (1998) for the same site. Measurements are made from a 30-m meteorological tower extending $7 \mathrm{~m}$ above the forest canopy. The tower is situated on moderately hilly terrain surrounded by several kilometers of forest, which has been relatively undisturbed in the predominant upwind directions (NW, W, SW) over the past 70 years (Urbanski et al., 2007). There are no paved roads within $1.5 \mathrm{~km}$ or towns within $10 \mathrm{~km}$. Sakai et al. (2001) estimate that ca. $80 \%$ of the turbulent fluxes are produced within $0.7-1 \mathrm{~km}$ of the tower. An analysis of the spatial heterogeneity of isoprene fluxes at the site by Goldstein et al. (1998) suggested that mean fluxes from the SW, NW, and NE quadrants, which together represented $82 \%$ of the data, agreed within $\pm 6 \%$. Fluxes from the SE, comprising the remaining $18 \%$ of the data, were lower than the average of the other three quadrants by $20 \%$, suggesting that emissions sources at the site are distributed relatively uniformly. The measurements presented here can be viewed in the context of a twenty-year-long data record from the site including meteorological conditions, eddy fluxes of heat, momentum, $\mathrm{H}_{2} \mathrm{O}, \mathrm{O}_{3}$, and $\mathrm{CO}_{2}$, and concentrations of $\mathrm{O}_{3}, \mathrm{CO}, \mathrm{CH}_{4}, \mathrm{NO}, \mathrm{NOy}$, and PAN (Wofsy et al., 1993; Munger et al., 1996; Goulden et al., 1996; Moore et al., 1996; Munger et al., 1998). In this study, non-continuous measurements were made between May and October of 2005 and 2007 to capture the majority of the growing season, when emissions of BVOCs are at their highest.

\subsection{Measurements of BVOCs}

An air sample was drawn from the top of the 30-m tower through $50 \mathrm{~m}$ of FEP Teflon tubing. In 2005, 0.25 in $\mathrm{OD} \times 0.156$ in ID tubing was used; this was changed to 0.375 in $\mathrm{OD} \times 0.250$ in ID tubing in 2007. Flow rates of $3.3 \mathrm{slpm}$ and $11.8 \mathrm{slpm}$ were used to achieve residence times of $11.5 \mathrm{~s}$ and $8.2 \mathrm{~s}$ in 2005 and 2007, respectively. A filter at the inlet removed particles from the sample flow. During the first few days of the 2007 season (days 149-151), a $0.5-\mu \mathrm{m}$ pore size filter was used but was found to produce a large pressure drop in the sample line so it was replaced. For all other measurements, a $2.0-\mu \mathrm{m}$ pore size $47-\mathrm{mm}$ diameter Zefluor teflon filter (Pall Corp.) was used. A small portion of the total flow $(\sim 300 \mathrm{sccm})$ was sub-sampled into the PTR-MS for analysis.

Measurements of VOC mixing ratios were made using Proton Transfer Reaction Mass Spectrometry (PTR-MS-hs, Ionicon Analytik) (Lindinger et al., 1998; Blake et al., 2009). Briefly, PTR-MS is a chemical ionization (CI) technique in which hydronium ions $\left(\mathrm{H}_{3} \mathrm{O}^{+}\right)$are used to protonate the analyte molecules, which are then selectively detected by mass spectrometry. Hydronium ions are produced by passing water vapor through the hollow cathode ion source. The reagent ions and sample gas enter a drift tube operated at an $E / N$ of $126 \mathrm{Td}$ where rapid (i.e., rate constant of ca. $2 \times 10^{-9} \mathrm{~cm}^{3} \mathrm{~s}^{-1}$ ) proton transfer occurs to species with a proton affinity greater than that of water $(165 \mathrm{kcal} / \mathrm{mol})$, including many VOCs. The protonated analyte ions are then filtered using a quadrupole mass spectrometer and detected. Low detection limits $(<20 \mathrm{pptv}$ for a $1 \mathrm{~s} \mathrm{dwell} \mathrm{time)} \mathrm{and} \mathrm{fast} \mathrm{time} \mathrm{response} \mathrm{(integration} \mathrm{times} \mathrm{as}$ short as $20 \mathrm{~ms}$ ) make the technique well suited to the eddy covariance flux method used here. Most compounds are detected at the parent ion mass, hence isomeric or isobaric compounds, such as the monoterpenes $\left(\mathrm{C}_{10} \mathrm{H}_{16}\right)$ or methyl vinyl ketone (MVK) and methacrolein ( $\mathrm{MAC}, \mathrm{C}_{4} \mathrm{H}_{6} \mathrm{O}$ ), cannot be distinguished by PTR-MS. In these cases, the total ion signal is attributed to the sum of the individual compounds. Species targeted during these studies included isoprene $(m / z=69,41)$ and its oxidation products MVK + MAC $(m / z=71)$, monoterpenes $(m / z=81,137)$, acetone $(m / z=59)$, methanol $(m / z=33)$, and $\operatorname{MEK}(m / z=73)$, as well as unknown BVOCs at $m / z=153$ and 155 .

The product ion signals were normalized to the corresponding reagent ion signal before the concentration was calculated to account for variations in the total ion signal between calibrations. Instrument sensitivity was determined by automated addition of known amounts of methanol, acetone, isoprene, and monoterpenes to the main sample flow ca. $50 \mathrm{~cm}$ upstream of the PTR-MS sample port every 3-4 h. Isoprene and monoterpenes (a 1:1 mixture of $\alpha$-pinene and $\beta$-pinene) at mixing ratios of ca. 5 ppmv in air held in separate high-pressure gas cylinders (Scott Specialty Gases) were added by passing a small flow (ca. $2 \mathrm{sccm}$ ) through a critical orifice and into the main sample flow, resulting in mixing ratios of 0.5 to $10 \mathrm{ppbv}$ (depending on the rate of the main flow). A permeation tube system was used to generate standards of methanol and acetone. The permeation tubes (VICI Metronics, Inc.) were held in a water bath at $35^{\circ} \mathrm{C}$ while $50 \mathrm{sccm}$ of dry nitrogen was passed over them. Permeation 
Table 1. Sensitivities, detection limits (1 s), dwell times and measurement cycle and covariance calculation parameters for each species and season.

\begin{tabular}{|c|c|c|c|c|c|c|c|}
\hline \multirow[b]{2}{*}{ Compound } & \multirow[b]{2}{*}{$m / z$} & \multicolumn{3}{|c|}{2005} & \multicolumn{3}{|c|}{2007} \\
\hline & & $\begin{array}{l}\text { Sensitivity } \\
\text { (ncps/ppbv) }\end{array}$ & $\begin{array}{l}\text { Detection Limit } \\
\text { (ppbv) }\end{array}$ & $\begin{array}{l}\text { Dwell Time } \\
\text { (s) }\end{array}$ & $\begin{array}{l}\text { Sensitivity } \\
\text { (ncps/ppbv) }\end{array}$ & $\begin{array}{l}\text { Detection Limit } \\
\text { (ppbv) }\end{array}$ & $\begin{array}{l}\text { Dwell Time } \\
\text { (s) }\end{array}$ \\
\hline Methanol & 33 & 14.8 & 1.4 & 0.5 & 14.1 & 1.3 & 0.2 \\
\hline Isoprene & 41 & & & & 2.8 & 0.9 & 0.2 \\
\hline Acetone & 59 & 28.3 & 0.13 & 0.5 & 28 & 0.14 & 0.2 \\
\hline Isoprene & 69 & 10.5 & 0.16 & 5 & 10.5 & 0.18 & 0.2 \\
\hline MVK + MAC & 71 & 27.9 & 0.06 & 1 & 28.1 & 0.06 & 0.2 \\
\hline MEK & 73 & 29.5 & 0.08 & 1 & 29.2 & 0.08 & 0.2 \\
\hline Monoterpenes & 81 & 13.4 & 0.09 & 1 & 13.1 & 0.09 & 0.2 \\
\hline Monoterpenes & 137 & 4.4 & 0.2 & 1 & 4.5 & 0.18 & 0.2 \\
\hline $\mathrm{C}_{10} \mathrm{H}_{16} \mathrm{O}$ & 153 & & & & 25.6 & 0.02 & 0.2 \\
\hline $\mathrm{C}_{10} \mathrm{H}_{18} \mathrm{O}$ & 155 & & & & 24.7 & 0.02 & 0.2 \\
\hline Total masses ${ }^{\mathrm{a}}$ & & 16 & & & 13 & & \\
\hline Total mass cycle time (s) & & 21.1 & & & 3.0 & & \\
\hline Number of points in covariance calculation & & 150 & & & 396 & & \\
\hline Covariance Integration Time (min) & & 56 & & & 27 & & \\
\hline Disjunct Sampling Error & & $2.5 \%$ & & & $1.5 \%$ & & \\
\hline
\end{tabular}

${ }^{a}$ Includes additional diagnostic masses not shown in the table.

rates of ca. $20 \mathrm{ng} \mathrm{min}^{-1}$ resulted in mixing ratios of 0.25 to $10 \mathrm{ppbv}$ after dilution in the main flow. The flow rate and temperature in the permeation tube system were held constant at all times to minimize passivation effects and the flow was vented via a three-way valve when not in use. Methyl vinyl ketone, methacrolein, and methyl ethyl ketone were calibrated periodically by direct injection using a method similar to that of Hanson et al. (2009). The sensitivities were determined relative to that of isoprene, and the ratios were used to determine sensitivity factors for these compounds between calibrations. The calibrated sensitivity generally was found to agree within $15 \%$ with that estimated using published proton-transfer rate constants for all compounds (Anicich, 2003; Ammann et al., 2004; Zhao and Zhang, 2004; Smith and Spanel, 2005).

The species detected at $m / z=153$ and 155 and their proton transfer rate constants are unknown, but Tani et al. (2003) detected a signal due to the oxygenated terpene camphor at $m / z=153$. They measured a proton transfer rate constant of $4.4 \times 10^{-9} \mathrm{~cm}^{3} \mathrm{~s}^{-1}$ for camphor, which agreed well with the value calculated using the trajectory method of Su and Chesnavich (Tani et al., 2003; Su and Chesnavich, 1982) and is applied here to the signals measured at $m / z=153$ and 155 . We emphasize that the resulting mixing ratios for species at these $m / z$ values should be viewed as approximate and may differ from the calculated values by up to a factor of 2 based on the uncertainty in the identity of these species and of the estimated proton transfer rate constant.

The transmission of ions through the PTR-MS system is known to be mass-dependent. Typically, the transmission is highest in the middle part of the $m / z$ range (ca. $m / z=80$ 95 ) and decreases at both low and high mass-to-charge ratios
(Steinbacher et al., 2004; Taipale et al., 2008; Kim et al., 2009). When sensitivities are determined directly using calibration standards, the transmission factor is accounted for and need not be known explicitly. It must be taken into account, however, when calculating concentrations from ionmolecule reaction parameters, such as was done here for the unknown terpenoids. The transmission as a function of $m / z$ was measured by sampling the vapor pressure directly over vials containing individual VOCs with a range of $m / z$ values, which converts the majority of the reagent ions to protonated VOC ions (Steinbacher et al., 2004). The transmission factor is defined as the ratio of the VOC- $\mathrm{H}^{+}$ion signal to the reagent ion signal, normalized to a maximum value of 1 . At the high end of the mass scale, the transmission factor was found to decrease from its peak value of 1 at $\mathrm{m} / z$ between 75 and 95 to ca. 0.4 at $m / z=158$. The transmission factor was measured periodically during the time span of the measurements and found to vary by ca. $\pm 20 \%$ at the high end of the mass range, but by less than $10 \%$ in the region between $m / z=55$ and 100 , where the majority of the compounds reported here are detected.

Background signals at each $m / z$ were determined by two methods: (1) the addition of humidified zero air at the entrance of the inlet while excluding ambient air and (2) removal of the analyte molecules using a catalytic converter consisting of platinum on alumina beads heated to $350{ }^{\circ} \mathrm{C}$. The concentrations determined using each of the two methods typically agree to within $10 \%$. The catalytic converter method was applied to the data reported here. Average sensitivities and detection limits corresponding to 2 times the standard deviation of the catalytic converter background countrate are shown in Table 1. 
Background cycles using zero air were also used to diagnose wall effects in the sample system for compounds at each monitored mass-to-charge ratio by assessing the signal decay after the zero air was switched on. Signals for compounds such as isoprene, monoterpenes, acetone, MVK+MAC, MEK, and methanol dropped rapidly (ca. $10 \mathrm{~s}$ ) to their background levels, indicating minimal wall effects. The signal at $m / z=153$ exhibited more significant tailing, with an apparent signal decay lifetime on the order of $30 \mathrm{~s}$. This suggests that the compound(s) detected at this massto-charge ratio interacts with the walls of the sample system, which, along with the issues of sensitivity and mass spectrometer transmission at the high end of the mass range discussed above, contribute to a large uncertainty range $(+100 \% /-50 \%)$ for this species.

Due to the inability of the PTR-MS to distinguish between isobaric molecules, possible interferences at the mass-tocharge ratios of targeted species must be considered. When calculating eddy covariance fluxes, however, many interferences can be ruled out because in order to contribute to the signal the interfering species must covary with the vertical wind (i.e., have a flux). This effectively restricts interferences to compounds with biogenic sources or those with significant deposition sinks, the latter of which would give rise to negative fluxes. Possible interferences for individual species are discussed below.

Previous studies have shown that methanol $(m / z=33)$, exhibits little fragmentation and no known interferences at the parent ion mass (Warneke et al., 2003; de Gouw et al., 2003a). The main interference for acetone $(m / z=59)$ is propanal, a species found mainly in urban areas, and hence unlikely to contribute to the flux from Harvard Forest (Warneke et al., 2003; de Gouw et al., 2003a).

Isoprene $(m / z=69)$ has several potential interferences, including biogenic species such as 2- and 3-methyl butanal and 1-penene-3-ol (Karl et al., 2001a, b; de Gouw et al., 2003a) and possibly anthropogenic species as well (de Gouw et al., 2003a). The anthropogenic species are expected to be minor interferences in a relatively remote location in close proximity to major isoprene sources, such as the Harvard Forest canopy (de Gouw and Warneke, 2007), but the biogenic species could contribute to the flux reported here. The biogenic VOC 2-methyl-3-buten-2-ol (MBO) has a parent ion at $m / z=87$, but the majority of the MBO signal is detected as a fragment with $m / z=69$ (Demarcke et al., 2010). MBO is emitted in large quantities by yellow, or hard, pines (genus Pinus, subgenus Pinus) found in western North America (Harley et al., 1998; Baker et al., 2001). Based on the observed fragmentation pattern, previous researchers using PTR-MS at certain sites in the western US have attributed the majority of the $m / z=69$ signal to MBO rather than to isoprene (Karl et al., 2002). None of the species found by Harley et al. (1998) to have significant MBO emissions are present at Harvard Forest, although some species that are present, such as red pine, were not tested. To rule out the pos- sibility that $\mathrm{MBO}$ contributed significantly to the flux signal at $m / z=69$ in this study, the flux at $m / z=87$ (MBO parent ion) was also determined and found to be more than two orders of magnitude smaller than that at $m / z=69$. Hence, we conclude that, for Harvard Forest, the signal at $m / z=69$ was dominated by isoprene and that MBO contributed at most a few percent.

$\mathrm{MVK}+\mathrm{MAC}$, the primary isoprene oxidation products, are isomers with the molecular formula $\mathrm{C}_{4} \mathrm{H}_{6} \mathrm{O}$. Hence, they are detected at the same mass-to-charge ratio $(m / z=71)$ and the signal at this mass is attributed to the sum of the two compounds. Although no explicit studies of possible interferences at this mass-to-charge ratio have been published, PTR-MS measurements have compared well with other techniques such as gas chromatography, suggesting minimal interferences (de Gouw and Warneke, 2007). Since the oxidation lifetime of isoprene (ca. $1.9 \mathrm{~h}$ at $[\mathrm{OH}]=1.5 \times 10^{6} \mathrm{~cm}^{-3}$ (Atkinson et al., 2006)) is long compared to the transport time out of the canopy (minutes or less), MVK and MAC are produced from isoprene oxidation primarily above the forest canopy and hence a relatively small positive or possibly a negative (deposition) flux would be expected for these compounds.

Methyl ethyl ketone $\left(\mathrm{MEK}, \mathrm{C}_{4} \mathrm{H}_{8} \mathrm{O}\right)$ is detected at $m / z=73$. Isobaric compounds such as butanal $\left(\mathrm{C}_{3} \mathrm{H}_{7} \mathrm{CHO}\right)$ and methyl glyoxal could also be detected at this mass-tocharge ratio, though they have not been observed in studies using chromatographic separation prior to PTR-MS detection (de Gouw et al., 2003a). Of two published intercomparisons of MEK measurements by PTR-MS with other methods, the more recent showed good agreement (de Gouw et al., 2003b, 2006). There is a known interference at $m / z=73$ due to the $\mathrm{H}_{3} \mathrm{O}^{+}\left(\mathrm{H}_{2} \mathrm{O}\right)_{3}$ cluster ion (de Gouw and Warneke, 2007). Under the instrumental conditions used here, the background ion signal at $m / z=73$ was typically ca. $25 \mathrm{cps}$, as compared to a daytime signal due to VOCs of $400 \mathrm{cps}$. The background, which includes the signal due to water, is monitored periodically and subtracted from the total signal. Hence, low-frequency signal due to $\mathrm{H}_{3} \mathrm{O}^{+}\left(\mathrm{H}_{2} \mathrm{O}\right)_{3}$ is removed. The flux signal measured for the $\mathrm{H}_{3} \mathrm{O}^{+}\left(\mathrm{H}_{2} \mathrm{O}\right)$ water cluster ion at $m / z=37$ and the relationship between water clusters observed at $m / z=37$ and 73 was used to estimate the contribution of water to the flux at $m / z=73$. This signal was $<10 \%$ of the total flux signal at $m / z=73$. In addition, the correlation between the total fluxes at $m / z=37$ and 73 was relatively weak, with a correlation coefficient $(R)$ of 0.4 for the 2005 data. This value is reasonable for the correlation of two compounds whose fluxes both increase during the day (e.g., the correlation coefficient between the flux at $\mathrm{m} / z=73$ and 59 is also 0.4 ). In contrast, the correlation between fluxes from ions derived from the same chemical species (i.e., fragments) is typically larger (e.g., monoterpene ion fluxes at $m / z=81$ and 137 have a correlation coefficient of 0.85 ). Furthermore, the correlation between $m / z=37$ and 73 is much weaker during fall than during summer, indicating different 
origins and a strong seasonal dependence of the $m / z=73$ flux. This suggests that the flux reported for $m / z=73$ is due to something other than water, likely a biogenic compound such as MEK.

Monoterpenes are detected at the parent ion mass at $m / z=137$ and the major fragment at $m / z=81$. Both of these masses are considered to be free of major interferences (de Gouw and Warneke, 2007). When the fluxes at $m / z=81$ and 137 are calculated independently the correlation coefficient $(R)$ between the two is found to be 0.85 , suggesting minimal contributions from other species to either mass. Because the monoterpene signal is due to the sum of several contributing isomers, each of which may have a slightly different fragmentation pattern, the sum of the $m / z=81$ and 137 signals is used to determine the total abundance.

Two unknown species were detected at $m / z=153$ and 155 . Since the compounds are unidentified, any potential interferences are also unknown. However, as stated previously, only compounds with a forest source or sink will give rise to a flux. Hence, it is reasonable to surmise that positive fluxes for these mass-to-charge ratios are due to sources of unidentified biogenic volatile organic compounds from the canopy. These could be primary emissions or secondary products from fast reactions of primary compounds within the canopy. The possible identities of these compounds will be discussed in more detail in Sect. 4.2.4.

\subsection{Eddy covariance technique}

Canopy-scale fluxes were determined from high-frequency vertical velocity and compound mixing ratio data using the disjunct eddy covariance method. In this technique, the products of the deviations from the mean mixing ratio and vertical wind are averaged over a time interval (ca. $30 \mathrm{~min}$ ) according to the equation:

$F=\left\langle w^{\prime} c^{\prime}\right\rangle=\frac{1}{N} \sum_{i=1}^{N} w_{i}{ }^{\prime} c_{i}^{\prime}$

where $c^{\prime}=c-\bar{c}, w^{\prime}=w-\bar{w}$ and $w, \bar{w}, c$, and $\bar{c}$ are the instantaneous and mean values of the mixing ratio and vertical wind, respectively, to determine the covariance, which is equal to the flux (McMillen, 1988). If the mixing ratio of the species of interest is higher in updrafts than in downdrafts, the covariance will be non-zero and there will be a net upward flux (and vice versa).

For eddy covariance calculations, the timescale of the individual measurements is required to be as fast as or faster than the timescale of the majority of the vertical eddies responsible for transport. In the case of the Harvard Forest canopy, greater than $90 \%$ of the flux can be captured with a sample time of $1 \mathrm{~s}$ (Sakai et al., 2001). Although multiple species detected at different mass-to-charge ratios can be measured using PTR-MS, the quadrupole mass analyzer monitors each mass sequentially rather than simultaneously.
This creates a virtual disjunct data set, in which the measurements at any individual mass are non-continuous and the sum of the dwell times at all masses determines the time interval between measurements at a single mass. Karl et al. (2002) showed that virtual disjunct data sets such as this can be used to determine eddy covariance fluxes with minimal error as long as the individual measurements in the disjunct dataset are uncorrelated. A number of other studies have used similar methods to determine BVOC fluxes from forest canopies (Rinne et al., 2001, 2007; Karl et al., 2004, 2007; Grabmer et al., 2004; Spirig et al., 2005; Lee et al., 2005; Holzinger et al., 2006). The disjunct sampling error increases with the length of time between measurements, restricting the length of the overall cycle and therefore the number of masses that can be included (Karl et al., 2002). A drawback of monitoring only a small number of masses in sequence is that it requires an a priori knowledge of which species are likely to have significant fluxes; fluxes of species at masses that are not included are missed.

During the summer of 2005, the PTR-MS was configured to measure the mixing ratios of the major biogenic VOCs and oxidation products (isoprene, monoterpenes, MVK + methacrolein) and oxygenated VOCs (acetone, methanol, MEK). In addition to the mass-to-charge ratios corresponding to these species, several diagnostic ions were included in the cycle. Long dwell times (1-5 s) were used to achieve high precision mixing ratio measurements. A measurement cycle including 16 masses was repeated every $21 \mathrm{~s}$ (Table 1 ). As a pilot study, these mixing ratio measurements were then used to calculate species fluxes. Although the measurement parameters were not ideal for flux calculations, the results demonstrated that covariances between BVOC mixing ratios and vertical wind at Harvard Forest could be readily determined. Based on the success of this trial, the instrument was configured specifically to obtain fluxes during the 2007 season. Shorter dwell times and fewer masses were used to optimize the suitability of the data for eddy covariance analysis. The measurement cycle included 13 species with dwell times of $0.2 \mathrm{~s}$ each, for a total cycle time of $3.0 \mathrm{~s}$. Compounds included in each data set, with their corresponding mass-to-charge ratios and dwell times are shown in Table 1. In 2007, the PTR-MS measurement cycle was interrupted every $108 \mathrm{~s}$ for $21 \mathrm{~s}$ to measure a larger range of masses with longer dwell times to obtain concentration information on a wider range of species. Vertical wind data was obtained from a sonic anemometer located less than $1 \mathrm{~m}$ away and at the same height as the PTR-MS sample line. Wind data was sampled at a rate of $10 \mathrm{~Hz}$.

The time interval over which the covariances were determined was chosen such that the elapsed time between calibration cycles (for which the high-frequency measurements were temporarily interrupted) was divided into an integral number of intervals. This ensured that all of the data was utilized and that all the intervals would have similar statistical characteristics. The averaging intervals used were 


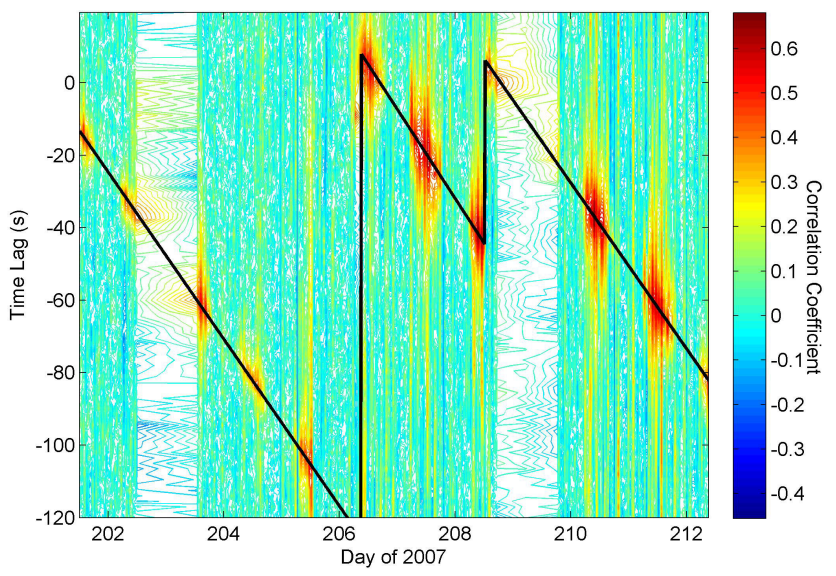

Fig. 1. Contour plot of the correlation coefficient as a function of the measurement time and the time lag between the vertical wind and isoprene mixing ratio. Large correlation coefficients are observed during the day when the isoprene flux is high. Due to acquisition of the wind and concentration data sets on two different computers using different software architectures, the time lag corresponding to the peak correlation drifts toward more negative values at a rate of $23 \mathrm{~s}$ per day and is reset periodically when a new anemometer data file is initiated. The lag at the start of each new data file is ca. $+8 \mathrm{~s}$, consistent with the transit time in the sample tube. The solid line is a fit to the lag yielding the peak correlation as a function of time and represents the lag value used to compute the isoprene flux.

approximately $30 \mathrm{~min}$ long; exact values for each data set are given in Table 1.

Before the covariance can be calculated, the mixing ratio and wind data sets must be synchronized. The data from the PTR-MS and from the sonic anemometer were stored on two different computers, both of which were synchronized to NIST time several times a day. However, the instrument control and data acquisition system used for the micrometerological measurements works off software-based timers that deviated from the synchronized hardware clocks and generated an offset that increases with time. In addition, there is a time lag in the PTR-MS signal relative to that of the sonic anemometer due to the residence time in the sample line. To correct for both of these effects, the actual lag for each integration period was determined by finding the maximum of the correlation coefficients between the two data sets calculated over a range of lag times. The calculation was performed for $m / z=69$, because isoprene has the largest emission rate and therefore the largest correlation with the vertical wind. Figure 1 shows an example of the correlation between the $m / z=69$ signal and vertical wind as a function of the lag time between the data sets and time. High correlation values are clearly seen during daytime hours, when the isoprene flux is large. The time lag used in the covariance calculation was determined by calculating a linear least-squares fit to the lag time of the maximum correlation as a function of sample time. The correction due to time drift is ca. $23 \mathrm{~s}$ per day and is reset periodically when a new sonic anemometer data file is initialized. For the conditions used in 2007, the apparent time offset between the data sets due to transit through the sample tube was ca. $8.3 \mathrm{~s}$, consistent with the residence time in the line. Lag times for other masses were determined relative to isoprene by first applying the isoprene lag and then finding the offset corresponding to the maximum of the lag correlation plot for each $\mathrm{m} / \mathrm{z}$ averaged over time. These are treated as constant offsets from the isoprene lag.

After adjusting the time lag, spikes are removed and the data $(w$ and $c$ ) in each interval are checked for discontinuities, dropouts, and unphysical values according to Vickers and Mahrt (1997). If any of these tests is positive, the data interval is flagged, but the data is not altered. Flagged intervals are later inspected and eliminated if an instrumental problem is found. The wind and mixing ratio data for each interval are detrended and the resulting covariances are adjusted to conform to a rotated coordinate plane that minimizes the mean vertical wind and aligns the $\mathrm{x}$-axis with the mean horizontal wind (McMillen, 1988).

To assess errors due to the long dwell times used in the 2005 data set, a hypothetical data set was constructed by averaging the high-frequency temperature and wind data to 1 and $0.2 \mathrm{~Hz}$ and calculating the covariance of $w$ and $T$. Dwell times of $5 \mathrm{~s}$ captured ca. $90 \%$ of the flux calculated using the high frequency data. A similar result can be obtained by examining $w^{\prime} T^{\prime}$ cospectra obtained from the forest data (Sakai et al., 2001), which show that ca. 3\% (10\%) of the total flux is carried by eddies with frequencies greater than $1 \mathrm{~Hz}$ $(0.2 \mathrm{~Hz})$. Hence, $\mathrm{a}+3 \%(+10 \%)$ correction was applied to the fluxes calculated from the 2005 data sets with dwell times of $1 \mathrm{~s}$ (5 s). No correction was applied to the 2007 data. The error due to disjunct sampling was calculated based on the method described by Karl et al. (2002) and found to be less than $2.5 \%$ (Table 1).

Previous work has shown that sampling conditions similar to those used here $(50 \mathrm{~m} \times 0.25$ in ID sample line; flow rate of ca. $12 \mathrm{slpm}$ ) are sufficient for capturing fluctuations at frequencies as fast as $5 \mathrm{~Hz}$ (Karl et al., 2002). Species such as those at $m / z=153$, which exhibited tailing in the sample line, will experience additional damping of the highfrequency signal due to interactions with the wall. In this case, the reported fluxes represent a lower limit.

One estimate of the uncertainty in the covariance can be obtained from the standard deviation of the covariance calculated over a range of lag times far away from the true lag (Spirig et al., 2005). This provides an estimate of the covariances calculated for uncorrelated data and hence of the minimum detectable true flux. For each flux data point, covariances were calculated for lags of $\pm(140-360) \mathrm{s}$ for both years of data. The error bars shown in the following figures represent the standard deviation of the resulting covariances at the 2- $\sigma$ level. 
Table 2. Dates of reported observations during the 2005 and 2007 measurement seasons. Mean temperature, PPFD, the average day of deciduous bud break, the day by which $50 \%$ of the leaves in the canopy reached $75 \%$ of their mature size (L75), and the peak LAI for each year are also given.

\begin{tabular}{|c|c|c|c|c|c|c|c|}
\hline Year & Dates & Days of Year & $\begin{array}{l}\text { Mean } T \\
\left({ }^{\circ} \mathrm{C}\right)\end{array}$ & $\begin{array}{l}\text { Mean PPFD } \\
\left(\mu \mathrm{mol} \mathrm{m}{ }^{-2} \mathrm{~s}^{-1}\right)\end{array}$ & $\begin{array}{l}\text { Mean deciduous } \\
\text { bud break (day \#) }\end{array}$ & L75 & Peak LAI \\
\hline \multirow[t]{2}{*}{2005} & 24 Jun-8 Sep & $175-250$ & 19.6 & 429 & \multirow[t]{2}{*}{128} & \multirow[t]{2}{*}{158} & \multirow[t]{2}{*}{3.6} \\
\hline & 9-18 Jul & 190-199 & 20.8 & 379 & & & \\
\hline \multirow[t]{7}{*}{2007} & 29 May-6 Sep & $149-249$ & 18.4 & 467 & \multirow[t]{7}{*}{129} & \multirow[t]{7}{*}{148} & \multirow[t]{7}{*}{3.6} \\
\hline & 29-31 May & $149-151$ & 17.4 & 609 & & & \\
\hline & 13-22 Jun & $164-173$ & 16.2 & 468 & & & \\
\hline & 5-7 Jul & $185-187$ & 17.9 & 400 & & & \\
\hline & 20-31 Jul & $201-212$ & 20.0 & 469 & & & \\
\hline & $15 \mathrm{Aug}$ & 227 & 12.3 & 50 & & & \\
\hline & 31 Aug-6 Sep & $243-249$ & 16.5 & 470 & & & \\
\hline
\end{tabular}

\section{Results}

Flux determinations are restricted to time periods during which both PTR-MS and wind data were available. These consisted of a total of 7 days in 2005 and 33 days in 2007. The specific time periods for each year are listed in Table 2 . The 2005 measurements were obtained in midsummer, but those from 2007 span the time period from early spring through late summer, providing information on the seasonal course of forest emissions.

The mean summer (JJA) temperatures, the average day of spring deciduous budbreak (defined as the date on which $50 \%$ of leaf buds have burst), the date when $50 \%$ of leaves have reached $75 \%$ of their final size (L75), and the mean summer deciduous leaf area index (LAI), for each year are also given in the table. The two years are similar in terms of climatological factors and metrics of the length of the growing season and forest productivity and fall within the typical range for Harvard Forest (Richardson et al., 2009; Richardson and O'Keefe, 2009). Urbanski et al. (2007) showed that during the 13-year period immediately preceding these measurements (1992-2004), Harvard Forest was experiencing increasing rates of net uptake, photosynthetic capacity, and ecosystem respiration, as well as increasing red oak biomass.

Compounds associated with biomass burning (acetonitrile, $m / z=42$ ) and anthropogenic emissions (benzene, $m / z=79$, and toluene, $m / z=93$ ) were measured by PTR-MS and generally found to be low, with mean mixing ratios of 62 , 50 pptv, and 55 pptv for acetonitrile, benzene, and toluene, respectively, indicating relatively little anthropogenic VOC influence at the site.

The time series of mixing ratios and fluxes of isoprene recorded during 2007 are shown in Fig. 2, along with temperature, photosynthetic photon flux density (PPFD), and the sensible heat flux $\left(w^{\prime} T^{\prime}\right)$ measured simultaneously at the tower. The correlation between temperature and PPFD and emission rate is readily apparent: a diel cycle is observed

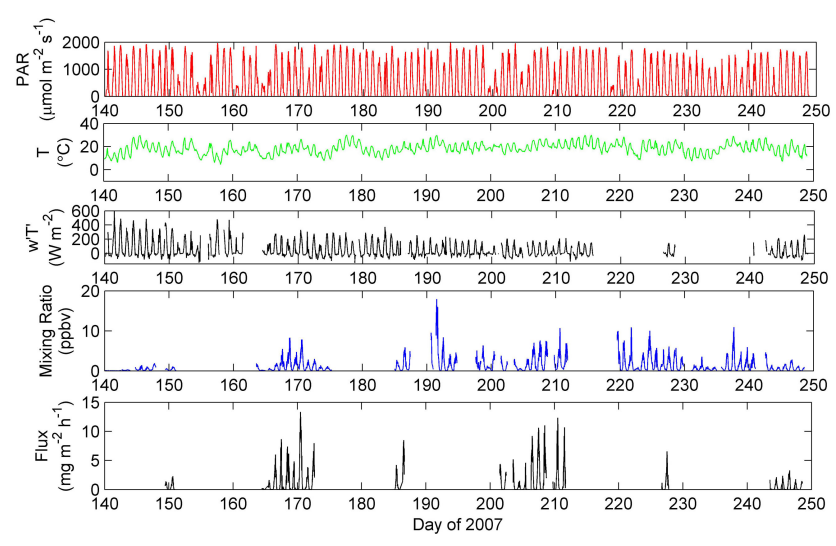

Fig. 2. Isoprene mixing ratio (4th panel) and flux (bottom panel) measurements for 2007. Also shown are photosynthetic photon flux density (PPFD, top panel), temperature (2nd panel), and sensible heat flux (3rd panel) measured at the tower.

in which emissions are highest during the day and lowest at night, emissions also tend to be highest on warm, sunny days. A similar diel cycle is observed for latent heat fluxes, though the seasonal pattern and day-to-day variability in the isoprene emissions is quite different. Isoprene emissions increase in early spring following leaf out, peak in midsummer, and decrease into fall.

Time series of methanol, acetone, methyl ethyl ketone, isoprene, and monoterpenes for a representative 6-day period in July 2007 are shown in Fig. 3. Diel cycles with mid-day maxima are observed for all species, though for the compounds with the smallest emissions the pattern is sometimes obscured by day-to-day variability.

For the oxygenated species, statistically significant negative fluxes, relative to the error range estimated as described above, are occasionally observed. These episodes generally occur in the morning (e.g., day 210 of 2007), but may also 

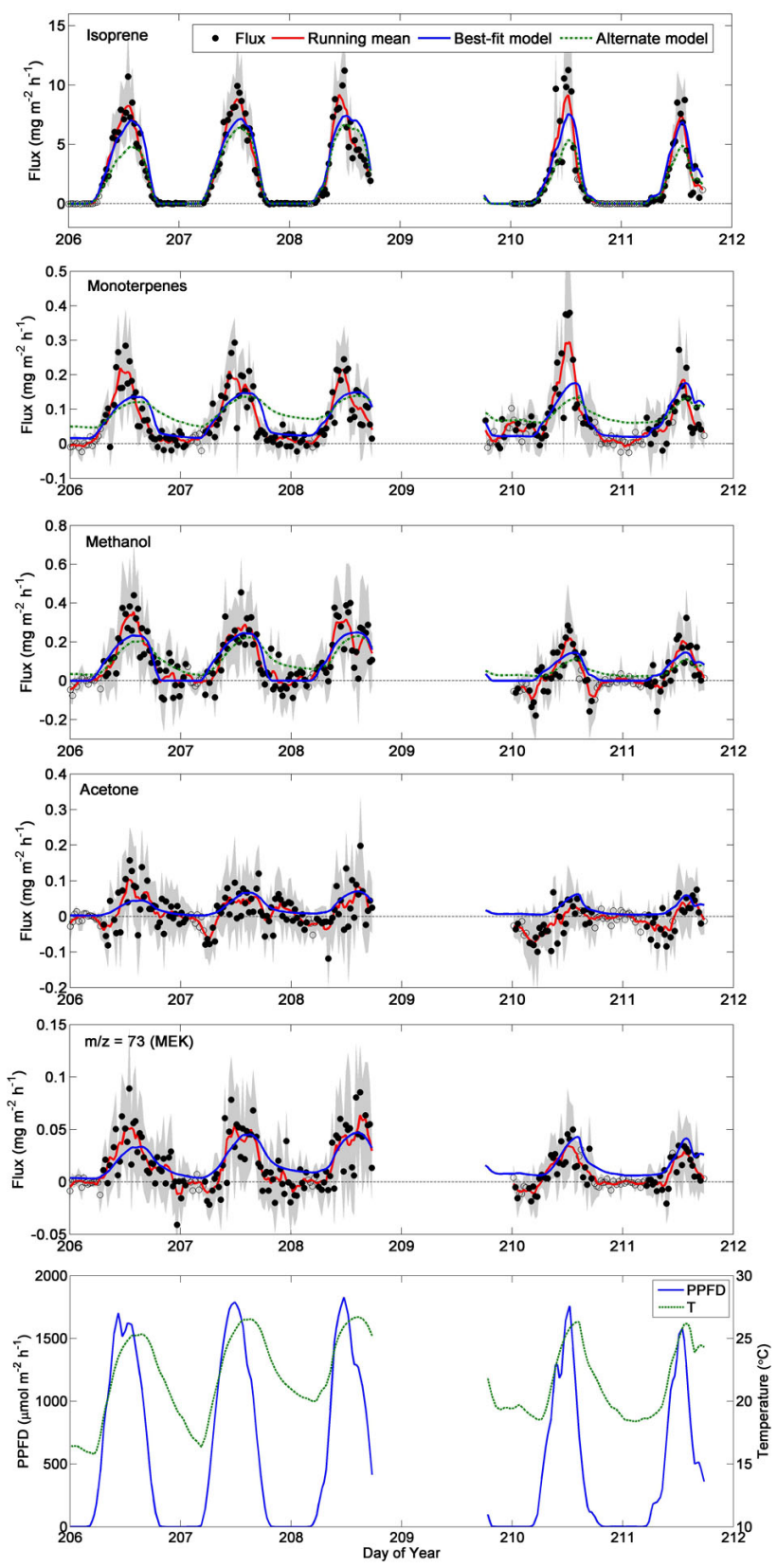

Fig. 3. Fluxes of VOCs computed for half-hour intervals during July, 2007. The grey shaded region is the $2 \sigma$ uncertainty range, computed from the covariance at times far away from the true lag as described in the text. Open points indicate time periods of stagnant air, as determined by values of $u^{*}$ below $0.2 \mathrm{~m} / \mathrm{s}$. The red line is a 5-point running mean of the flux measurements. The best model fit and an alternate are also shown. The models used are as follows: isoprene - MEGAN algorithm (best), G93 algorithm (alt); monoterpenes - G93 algorithm with Eq. (4) fit to nighttime data (best), Eq. (4) only (alt); methanol - G93 (best); Eq. (4) (alt); acetone - Eq. (4) (best); MEK - Eq.. (4) (best). Temperature and PPFD measured during this time period are also shown. appear at other times. Before concluding that deposition is occurring, uncertainties that could lead to the observed negative fluxes or other anomalies are considered.

Assuming negligible horizontal advection, the mass balance is given by the following equation,

$F_{i}^{h}+\frac{\partial}{\partial t} \int_{0}^{h} C_{i}(z) d z=\int_{0}^{h} P_{i}(z) d z-\int_{0}^{h} L_{i}(z) d z-\int_{0}^{h} D_{i}(z) d z$

The first term on the left hand side is the turbulent flux of species $i$ at measurement height $h$ and the second term represents storage within the canopy. The sum of the two should equal the sum of $P, L$ and $D$, which are the height-dependent production, loss and deposition within the canopy. The storage within the canopy was estimated by assuming a constant profile shape so that the column mean concentration is proportional to the observed concentration at the measurement height:

Storage $=\frac{\left[C\left(t_{i}\right)-C\left(t_{i-1}\right)\right] \times h}{\Delta t}$,

where $h=30 \mathrm{~m}$ and $\Delta t=1 \mathrm{~h}$ (Papale et al., 2006). This term was nearly negligible relative to the observed turbulent fluxes. Hence, storage cannot account for the "missing" flux.

Anomalous negative fluxes could arise from the breakdown of the assumptions of the eddy covariance method due to a stagnant boundary layer. Stagnant periods can be identified using a threshold value of the friction velocity, $u^{*}$, of $0.2 \mathrm{~m} \mathrm{~s}^{-1}$ (Urbanski et al., 2007). Flux data points for which $u^{*}$ fell below this threshold are shown with open symbols in Fig. 3. Most of these occur at night, when emission rates of biogenic VOCs are low, and hence the error arising from inaccurate flux calculations is small. Occasional stagnant periods occur during the day, however. For example, during a period on day 193 of 2005 when negative acetone fluxes were observed, $u^{*}$ also dropped to below $0.2 \mathrm{~m} \mathrm{~s}^{-1}$. However, the fact that the hydrocarbons do not exhibit negative fluxes during these periods suggests that, in addition to the soundness of the method, the chemical properties of the compound also play a role.

To determine the effect of fluxes obtained during stagnant periods on the results, diel averages were calculated both including and excluding points for which $u^{*}$ is below the threshold. For all species, the diel averages with low $u^{*}$ points excluded are not significantly different from those that include all data points. Hence, points for which $u^{*}$ falls below the threshold have not been excluded from the data set, but it is worth noting that the suppression of turbulent mixing leads to a greater uncertainty in the eddy flux during these periods.

For most of the episodes during which negative fluxes of methanol, acetone, and MEK were observed the eddy flux method appeared reliable. For example, Fig. 4 shows a plot of the covariance of acetone mixing ratio and vertical wind 
Table 3. Summer mid-day average fluxes and standard emission rates of each species. Standard emission rates are obtained using the model and other fit parameters listed below.

\begin{tabular}{|c|c|c|c|c|c|c|c|}
\hline & \multirow[t]{2}{*}{ Year } & \multirow{2}{*}{$\begin{array}{l}\text { Summer (JJA) } \\
\text { mid-day avg flux } \\
\left(\mathrm{mg} \mathrm{m}^{-2} \mathrm{~h}^{-1}\right)\end{array}$} & \multirow[t]{2}{*}{ Model } & \multirow{2}{*}{$\begin{array}{l}\text { Light-dep } \\
E_{\mathrm{s}} \\
\left(\mathrm{mg} \mathrm{m}^{-2} \mathrm{~h}^{-1}\right)\end{array}$} & \multicolumn{2}{|c|}{$T$-dependent (Eq. 4) } & \multirow[b]{2}{*}{$R$} \\
\hline & & & & & $\begin{array}{l}E_{\mathrm{s}} \\
\left(\mathrm{mg} \mathrm{m}^{-2} \mathrm{~h}^{-1}\right)\end{array}$ & $\begin{array}{l}\beta \\
\left(\mathrm{K}^{-1}\right)\end{array}$ & \\
\hline \multirow{2}{*}{ Isoprene } & 2005 & 5.30 & MEGAN & $9.9-11.5$ & & & 0.90 \\
\hline & 2007 & 4.40 & MEGAN & $3.7-17.2$ & & & 0.93 \\
\hline \multirow[t]{2}{*}{ Monoterpenes } & 2005 & 0.21 & G93+Eq. (4) & $0.14-0.37$ & 0.045 & 0.10 & 0.84 \\
\hline & 2007 & 0.15 & G93+Eq. (4) & $0-0.54$ & 0.063 & 0.10 & 0.69 \\
\hline \multirow[t]{2}{*}{ Methanol } & 2005 & 0.14 & G93 & $0.24-0.31$ & & & 0.78 \\
\hline & 2007 & 0.19 & G93 & $0.22-1.8$ & & & 0.80 \\
\hline \multirow[t]{2}{*}{ Acetone } & 2005 & 0.15 & Eq. (4) & & 0.68 & 0.26 & 0.47 \\
\hline & 2007 & 0.028 & Eq. (4) & & 0.20 & 0.33 & 0.33 \\
\hline \multirow[t]{2}{*}{$m / z=73(\mathrm{MEK})$} & 2005 & 0.045 & Eq. (4) & & 0.12 & 0.23 & 0.60 \\
\hline & 2007 & 0.028 & Eq. (4) & & 0.10 & 0.25 & 0.49 \\
\hline $\mathrm{m} / \mathrm{z}=153$ & 2007 & 0.005 & Eq. (4) & & 0.013 & 0.21 & $0.89^{\mathrm{a}}$ \\
\hline
\end{tabular}

${ }^{a} R$ value for fit to binned data.

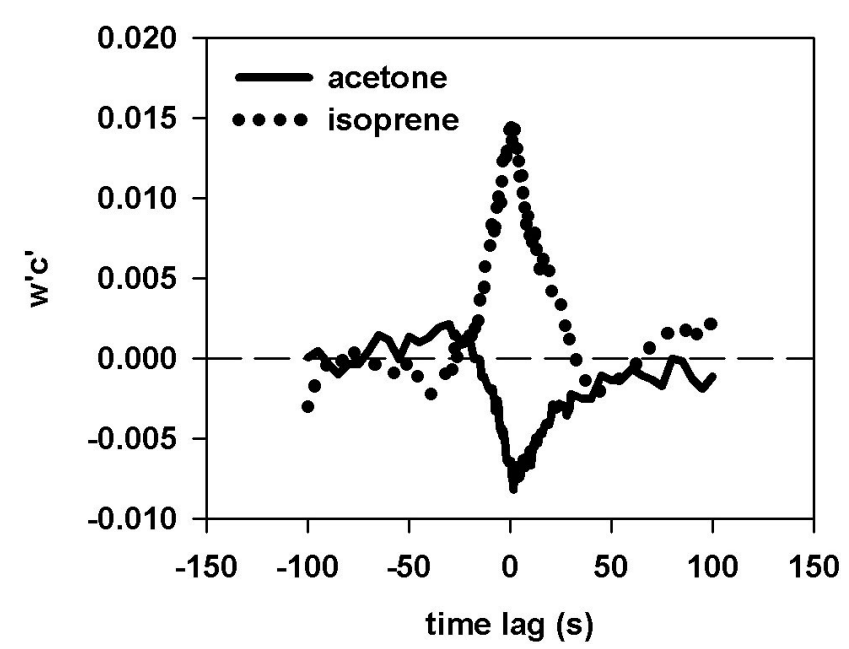

Fig. 4. Lag covariance plot of acetone and isoprene for the morning of day 210 of 2007 , during which negative fluxes of acetone were observed.

calculated as a function of the lag time between datasets during the morning of day 210 of 2007 . The lag covariance for isoprene during the same period is also shown. The plot clearly shows a coherent, well behaved negative covariance for acetone that coincides with the positive covariance for isoprene. Hence, these appear to be valid measurements of net uptake of these compounds by the forest.

Negative fluxes of oxygenated VOCs above forest canopies have been observed in other studies (Karl et al., 2005; Seco et al., 2007) and are consistent with bidirectional exchange. Compounds such as methanol, acetone, and MEK are somewhat soluble in water within the leaf and on its surfaces (Henry's Law constants at $298 \mathrm{~K}$ of $0.46,4.1$, and
$6.8 \mathrm{~Pa} \mathrm{~m}^{3} \mathrm{~mol}^{-1}$, respectively (Sander, 1999)). Gas-phase mixing ratios of these compounds will respond to changes in aqueous-phase concentrations from production or consumption in the mesophyll and to changes in water volume on canopy surfaces. Thus, they will exhibit either positive or negative fluxes depending on whether ambient concentrations are above or below the partial pressure in equilibrium with aqueous concentrations in the mesophyll (compensation point). Because canopy-scale flux measurements detect the net ecosystem exchange, they reflect the sum (either positive or negative) of these production and removal processes.

Methanol and MEK exhibit occasional episodes of negative fluxes, such as those indicated above, and the diel average fluxes of these species reach a minimum in the hours before daybreak, but the minimum diel mean value does not differ significantly from zero. In contrast, acetone exhibited a more regular pattern of early morning deposition, particularly in 2007, as evidenced by both the flux time series shown in Fig. 3 and the diel average cycle in Fig. 5. The factors controlling the uptake of OVOCs by forests are not well understood, and hence there is no specific mechanism to explain the seemingly large uptake of acetone by the forest in 2007 .

Figure 5 shows the diel mean and the statistical distribution (median, highest and lowest quartiles and deciles) of fluxes, along with the mean mixing ratios for each species during 2005 and 2007. Diel means of temperature and PPFD for the same period are shown in Fig. 6. Mean summer midday fluxes for both years are reported in Table 3 . The highest emission rates were observed for isoprene, which had mean summer mid-day fluxes of 5.3 and $4.4 \mathrm{mg} \mathrm{m}^{-2} \mathrm{hr}^{-1}$ (JJA) in 2005 and 2007, respectively, but reached values as high as $13.5 \mathrm{mg} \mathrm{m}^{-2} \mathrm{hr}^{-1}$. This compares reasonably well with previous measurements of the isoprene emission rate at the same site by Goldstein et al. (1998), who found the summer 

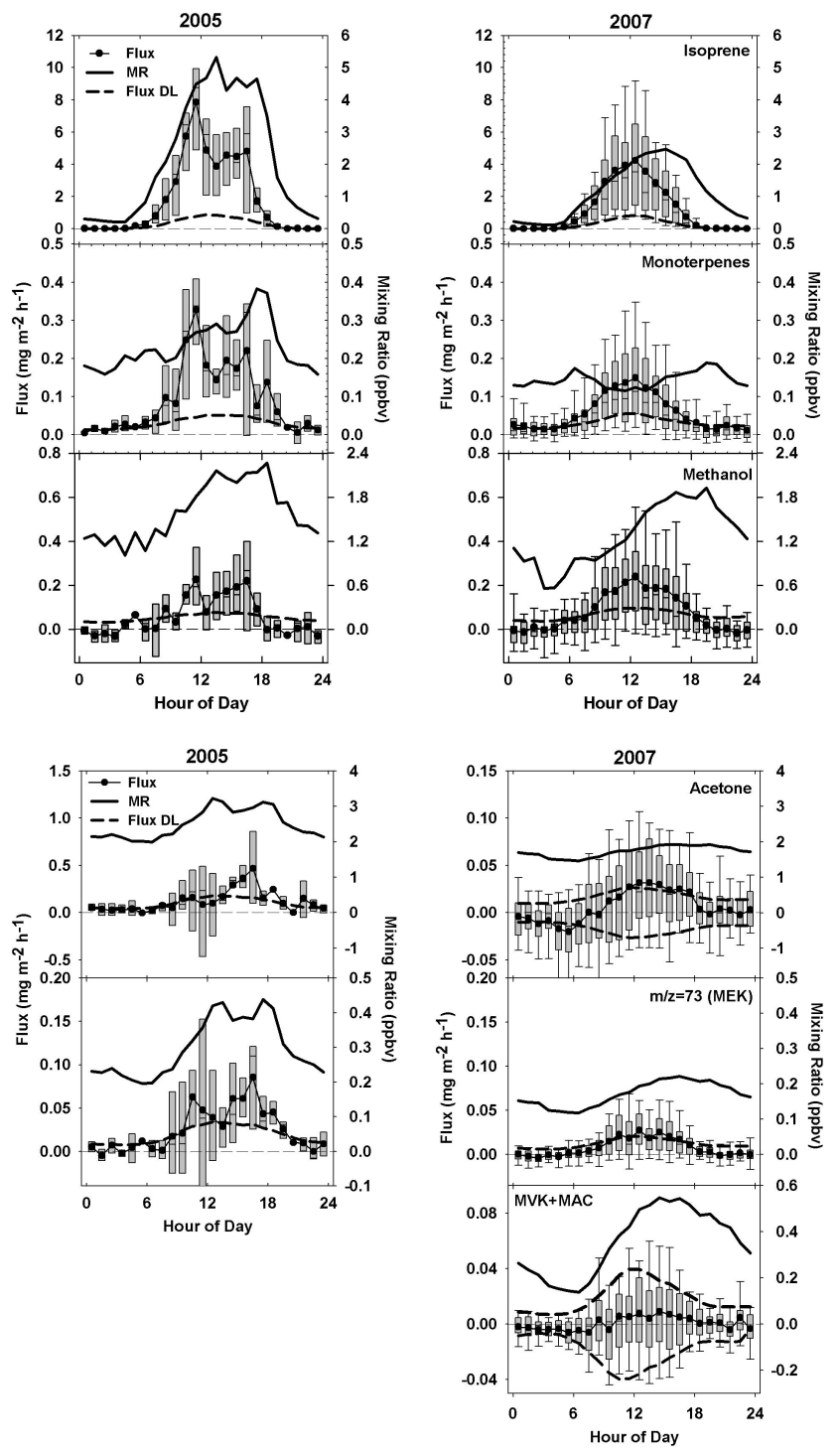

Fig. 5. Diel cycles of mean fluxes (filled circles) and mixing ratios for a range of BVOCs during 2005 (left) and 2007 (right). The box and whisker plots show the median (horizontal line), upper and lower quartiles (shaded boxes), and highest and lowest deciles (error bars) of the individual measurements. Due to the small number of measurements in 2005, only the quartiles can be determined. The flux detection limits for each species, calculated from the covariance far away from the true lag as described in the text, are also shown. The vertical axes are the same in both years for all species except acetone, for which the y-axis is expanded by a factor of 10 in 2005 relative to 2007. The mean temperature and PPFD for the time period of the observations are shown in Fig. 6 .

mid-day average emissions to be ca. $6.5 \mathrm{mg} \mathrm{m}^{-2} \mathrm{hr}^{-1}$ using a flux-gradient similarity approach.

The average monoterpene flux from the forest is about 20 times lower than that of isoprene, with summer mid-day mean values of 0.21 and $0.15 \mathrm{mg} \mathrm{m}^{-2} \mathrm{hr}^{-1}$ in 2005 and 2007 , respectively. Monoterpene fluxes have not been measured
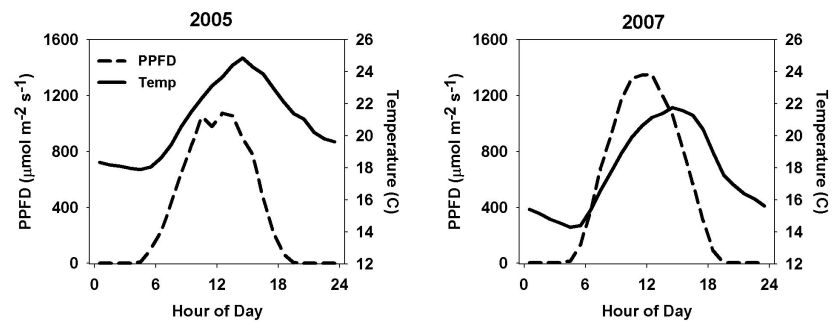

Fig. 6. Diel cycles of temperature and PPFD corresponding to the diel average fluxes shown in Fig. 5.

previously at Harvard Forest, but these results are broadly consistent with studies at a variety of other sites. Monoterpene fluxes measured at midlatitude coniferous forests range from 0.1 to $1.1 \mathrm{mg} \mathrm{m}^{-2} \mathrm{hr}^{-1}$ (Schade and Goldstein, 2001; Grabmer et al., 2004; Spirig et al., 2005; Holzinger et al., 2006; Graus et al., 2006; Rinne et al., 2007). VOCs emissions from a deciduous-dominated ecosystem such as Harvard Forest may differ significantly from those from the coniferous ecosystems cited above. The comparisons here and elsewhere in the paper to BVOC emissions at forest sites with larger fractions of coniferous species are provided with this caveat in mind but are included because of the relatively small number of published studies at comparable midlatitude deciduous-dominated forests. At a deciduous forest in Germany composed primarily of beech, birch and oak, Spirig et al. (2005) reported average daytime emission rates of $0.3 \mu \mathrm{g} \mathrm{m}^{-2} \mathrm{~s}^{-1}\left(1.1 \mathrm{mg} \mathrm{m}^{-2} \mathrm{hr}^{-1}\right)$, somewhat larger than those seen here. Ortega et al. (2007) predicted a canopy-scale monoterpene emission rate of $0.11-0.22 \mathrm{mg} \mathrm{m}^{-2} \mathrm{hr}^{-1}$ based on a branch enclosure study at a mixed northern hardwood forest in Michigan. The good agreement with the latter value is reasonable considering the climate and species distribution at Harvard Forest are probably most similar to the Michigan site.

The emission rates of the oxygenated VOCs methanol and acetone were of the same order of magnitude as the monoterpenes, with mean summer mid-day fluxes of 0.14 and $0.19 \mathrm{mg} \mathrm{m}^{-2} \mathrm{hr}^{-1}$ of methanol and 0.15 and $0.03 \mathrm{mg} \mathrm{m}^{-2} \mathrm{hr}^{-1}$ of acetone in 2005 and 2007, respectively. Fluxes of MEK were a factor of 3 to 5 lower than those of the monoterpenes, averaging $0.05 \mathrm{mg} \mathrm{m}^{-2} \mathrm{~h}^{-1}$ in 2005 and $0.03 \mathrm{mg} \mathrm{m}^{-2} \mathrm{hr}^{-1}$ 2007. Other studies at North American and European sites have found fluxes in the range of 0.08 to $1 \mathrm{mg} \mathrm{m}^{-2} \mathrm{hr}^{-1}$ for methanol and 0.1 to $2.5 \mathrm{mg} \mathrm{m}^{-2} \mathrm{hr}^{-1}$ for acetone (Baker et al., 2001; Schade and Goldstein, 2001; Karl et al., 2002, 2003, 2005; Spirig et al., 2005; Rinne et al., 2007). The values reported here largely fall within but on the lower end of the previously observed range. In addition to environmental conditions, differences in tree species distributions are also likely to contribute to the variation in emission rates reported at different sites. Although to our knowledge there are no other quantitative reports of canopy-scale MEK 
fluxes, Karl et al. (2005) detected a compound at $m / z=73$ with a source in the middle and top of the canopy using PTRMS. They attributed the signal to $\mathrm{C} 3$ and $\mathrm{C} 4$ carbonyls (including MEK) with biogenic or atmospheric sources.

For most species, the diel average fluxes obsered in 2005 fall on the high end of the range of values observed in 2007. As the emission rates are not normalized for light and temperature, these differences are in part due to the specific meteorological conditions during the sampling periods. The data for 2005 was recorded in early July, the peak emissions season for most species, during a period where the maximum midday temperatures reached as high as $29^{\circ} \mathrm{C}$. In contrast, the 2007 data was obtained between May and September. The maximum temperature observed during the 2007 observation period was $27^{\circ} \mathrm{C}$, and the average temperature was even lower. Methanol is an exception to the general pattern, exhibiting a higher diel average flux in 2007 than 2005. This is primarily because the 2007 average includes data from early spring, when methanol emissions are at their peak, whereas the 2005 average does not. The seasonal pattern in methanol emissions will be discussed further in Sect. 4.2.1.

For acetone and, to a lesser extent, MEK, the difference between the 2005 and 2007 diel averages is larger than can be explained based on temperature differences alone. In comparing fluxes of acetone between 2005 and 2007 using Fig. 5, it should be noted that the vertical axis for the 2005 data has been expanded by a factor of 10 relative to the 2007 data. The differences are also apparent in the summer midday averages reported above. These differences, and the relationship between OVOC fluxes and driving variables such as temperature and light will be investigated in more detail in Sect. 4.2.

MVK and MAC are oxidation products of isoprene, produced primarily above the canopy, and hence not expected to exhibit a large positive flux. Past studies have reported negative (Karl et al., 2005; Karl et al., 2004; Andreae et al., 2002; Karl et al., 2010) or small, sporadic positive (Spirig et al., 2005) fluxes of MVK + MAC from forest canopies. As Fig. 5 shows, no significant net flux in either direction was detected in this study. The mixing ratios of MVK + MAC above the canopy were relatively low (0.1-0.6 ppbv), thus it is possible that no flux was observed because the ambient concentrations were close to the compensation point (Karl et al., 2010).

The mean diel cycle for $m / z=153$ during June and July is compared to that from September in Fig. 7. The error bars are propagated from the flux uncertainty estimates obtained from the covariance far from the true lag as described in Sect. 2.3. A statistically significant flux with a robust diel cycle is observed during the summer but absent in the fall. We attribute this signal to an unknown BVOC, possibly an oxygenated terpene or methyl salicylate. Using an estimated proton transfer rate constant to calculate the species mixing ratio as described above, the mean daytime flux of the species at this mass-to-charge ratio is estimated to be $5 \mu \mathrm{g} \mathrm{m} \mathrm{m}^{-2} \mathrm{~h}^{-1}$,

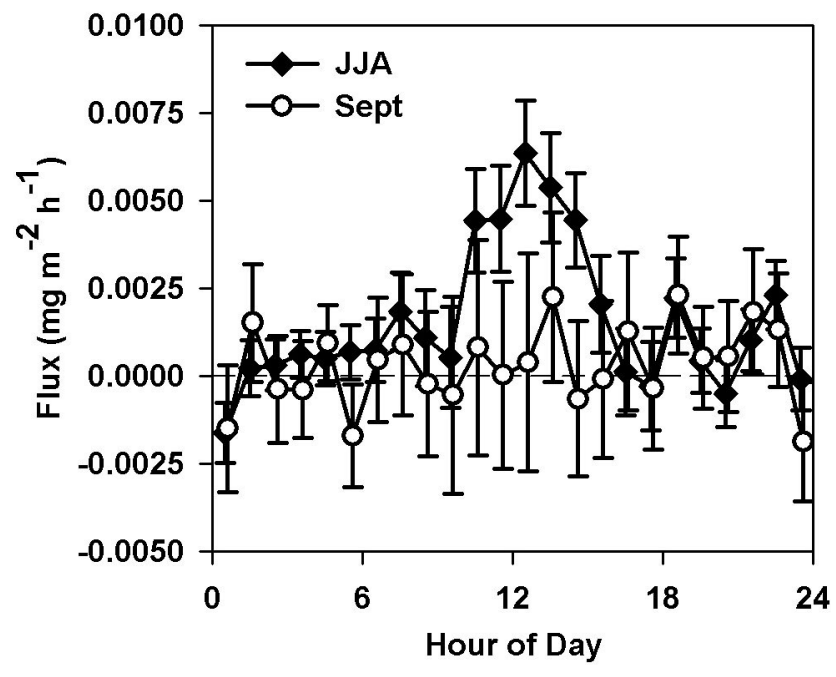

Fig. 7. Diel average flux at $m / z=153$ during June, July, and August, compared to that for September. The error bars are the 2- $\sigma$ uncertainty estimate derived from the covariance at lags far away from the true lag, as described in the text.

which is ca. $3 \%$ by mass of the monoterpene flux for the same time period.

The diel patterns in mixing ratios for all species can also be seen in Fig. 5. Although for some species (e.g., isoprene) the mid-day maximum emission rate is reflected in a maximum in mixing ratio at the same time, this is not true for all compounds. The mixing ratio depends not only on the shape and magnitude of the diel emissions function, but also on loss processes such as chemical reaction, advection, vertical mixing, and deposition, which differ among the species. In particular, though emissions generally increase during the day, the boundary layer height is also increasing during this time, resulting in a larger mixing volume. Oxidation rates, especially due to reaction with $\mathrm{OH}$, also increase during the day. Hence, for compounds with small emission rates, or emission rates controlled primarily by temperature (which, unlike PPFD, does not go to zero at night), mixing ratios may actually decrease during the day, as observed for monoterpenes. This is a commonly observed pattern in forest environments (e.g., Fehsenfeld et al., 1992; Bouvier-Brown et al., 2009).

Overall, isoprene accounts for approximately $89 \%$ by mass of the total emissions of VOCs measured at the site, with monoterpenes, methanol, acetone, and MEK contributing approximately $4 \%, 5 \%, 2 \%, 0.5 \%$, respectively. 


\section{Discussion}

\subsection{Isoprenoids}

\subsubsection{Isoprene}

The diel average emissions of isoprene, shown in Fig. 5, exhibit a large amplitude, with essentially zero emissions at night and a large source during the day. This behavior implies that, as expected, isoprene emissions from Harvard Forest depend on both light and temperature (Guenther et al., 1993; Goldstein et al., 1998). Guenther et al. $(1993,2006)$ define activity factors, dimensionless functions of temperature and PPFD, for describing this dependence. The activity factors can also be used to normalize observed fluxes to standard conditions, usually defined as $T=303 \mathrm{~K}$ and PPFD $=1000 \mu \mathrm{mol} \mathrm{m}{ }^{-2} \mathrm{~s}^{-1}$. Here, two different algorithms were used to determine the activity factors. These are the original algorithm (G93) proposed by Guenther et al. (1993) and the improved parameterization used in MEGAN (Guenther et al., 2006). Among other changes, the MEGAN algorithm used here includes terms to account for the effect of temperature and PPFD over the 1- and 10-day periods prior to the measurement. In contrast to the full MEGAN model implementation, a canopy environment model was not used here to determine the fractions of sunlit and shaded leaves; instead, $100 \%$ sunlit leaves were assumed. A comparison of the two models with the observed isoprene fluxes (Fig. 3) showed that the G93 algorithm tends to overestimate the flux at low values and underestimate it at high values. In contrast, the MEGAN algorithm is better able to capture these variations. Hence, the MEGAN algorithm was used to normalize the measured isoprene fluxes, although it is important to note that the resulting normalized values do not correspond to the commonly used standard conditions (in MEGAN, the canopy environment activity factor, which accounts for variations in $T$ and PPFD, equals 1 at $T=297 \mathrm{~K}$ and PPFD $=1500 \mu \mathrm{mol} \mathrm{m} \mathrm{m}^{-2} \mathrm{~s}^{-1}$; in most studies based on the G93 algorithm, standard conditions of $T=303 \mathrm{~K}$ and PPFD $=1000 \mu \mathrm{mol} \mathrm{m}{ }^{-2} \mathrm{~s}^{-1}$ are used), and hence are not directly comparable with normalized fluxes obtained using the G93 algorithm.

To assess variation over time, emission rates at standard conditions were determined from the best fit slope for linear regressions of measured isoprene fluxes with the MEGAN algorithm in 2-3 day intervals. The normalized emission rates ranged from 3.7 to $17.2 \mathrm{mg} \mathrm{m}^{-2} \mathrm{hr}^{-1}$ for measurements made in July 2005 and between May and September 2007, with average values of $13.1 \mathrm{mg} \mathrm{m}^{-2} \mathrm{hr}^{-1}$ in midsummer. Normalizing to standard conditions of $T=303 \mathrm{~K}$ and PPFD $=1000 \mu \mathrm{mol} \mathrm{m}^{-2} \mathrm{~s}^{-1}$ using the G93 algorithm yields a midsummer average of $9.4 \mathrm{mg} \mathrm{m}^{-2} \mathrm{hr}^{-1}$. This compares favorably with the midsummer standard emission rate for this location reported previously by Goldstein et al. (1998) (ca. $12 \mathrm{mg} \mathrm{m}^{-2} \mathrm{hr}^{-1}$ ).
The model predictions obtained by combining the standard emission rates for each interval with the light- and temperature-dependent terms are shown for both G93 and MEGAN algorithms together with the data for a typical time period in Fig. 3. The MEGAN algorithm is clearly a better match to the data. Although the model is reasonably good at reproducing the observations, it does seem to underpredict the emission rate during the mid-day peak. This could be due in part to the use of air rather than leaf temperature and the assumption of $100 \%$ sunlit leaves rather than use of a canopy environment model. Keenan et al. (2009) also compared the MEGAN algorithm to measured isoprene fluxes. Their results indicate that, while the MEGAN algorithm performed well on average, there were discrepancies between the model and measured values on short time scales. In particular, in comparison with data from a site in France, the model tended to overestimate fluxes during the afternoon, whereas it underestimated the highest daily integrated fluxes observed at a site in Michigan (Keenan et al., 2009).

The normalized emission rates are plotted as a function of the day of the year in Fig. 8. Standard rates from the two years are in good agreement. The figure shows that even when using the MEGAN algorithm, which accounts for temperature and light levels over the 10 days prior to the measurement, there remains a significant seasonal component to the variation in the standard emission. Normalized emission rates are lowest in May, increase to their maximum values in early June, and then appear to decrease gradually over time, though there is some variability in the values.

MEGAN uses a combination of leaf area index (LAI) and a leaf age factor, $\gamma_{\text {age }}$, to account for seasonal effects. Here, the leaf age factor was determined based on LAI measurements from the tower site (Urbanski et al., 2007), as described by Guenther et al. (2006). The induction time between bud break and the onset of isoprene emissions, $t_{i}$, was determined from the PTR-MS measurements of isoprene mixing ratio, which began to increase on day 142 of 2007, resulting in a value of 13 days. In comparison, the standard value of $t_{\mathrm{i}}$ recommended by Guenther et al. (2006) is 12 days. The default value of 28 days was used for $t_{\mathrm{m}}$, the time required for the leaves to reach peak isoprene emissions. After the induction period, the leaf age factor increases from zero to its maximum value of 1.1 over a period of ca. 20 days. It begins to decrease around day 230, and levels off at around 1, the value for old leaves. When combined with LAI, the major effect of the leaf age factor is to delay the onset of isoprene emissions by an amount corresponding to the induction period and to increase the peak midsummer value by about $10 \%$. It has virtually no effect on the predicted cessation of isoprene emissions in the fall.

Values of LAI and LAI $\times \gamma_{\text {age }}$ are shown together with the normalized fluxes in Fig. 8. LAI data for 2007 are used, but LAI for 2005 was very similar. The leaf age factor does a good job of predicting the delay in the onset of isoprene emissions in the spring relative to leafout. The observations 

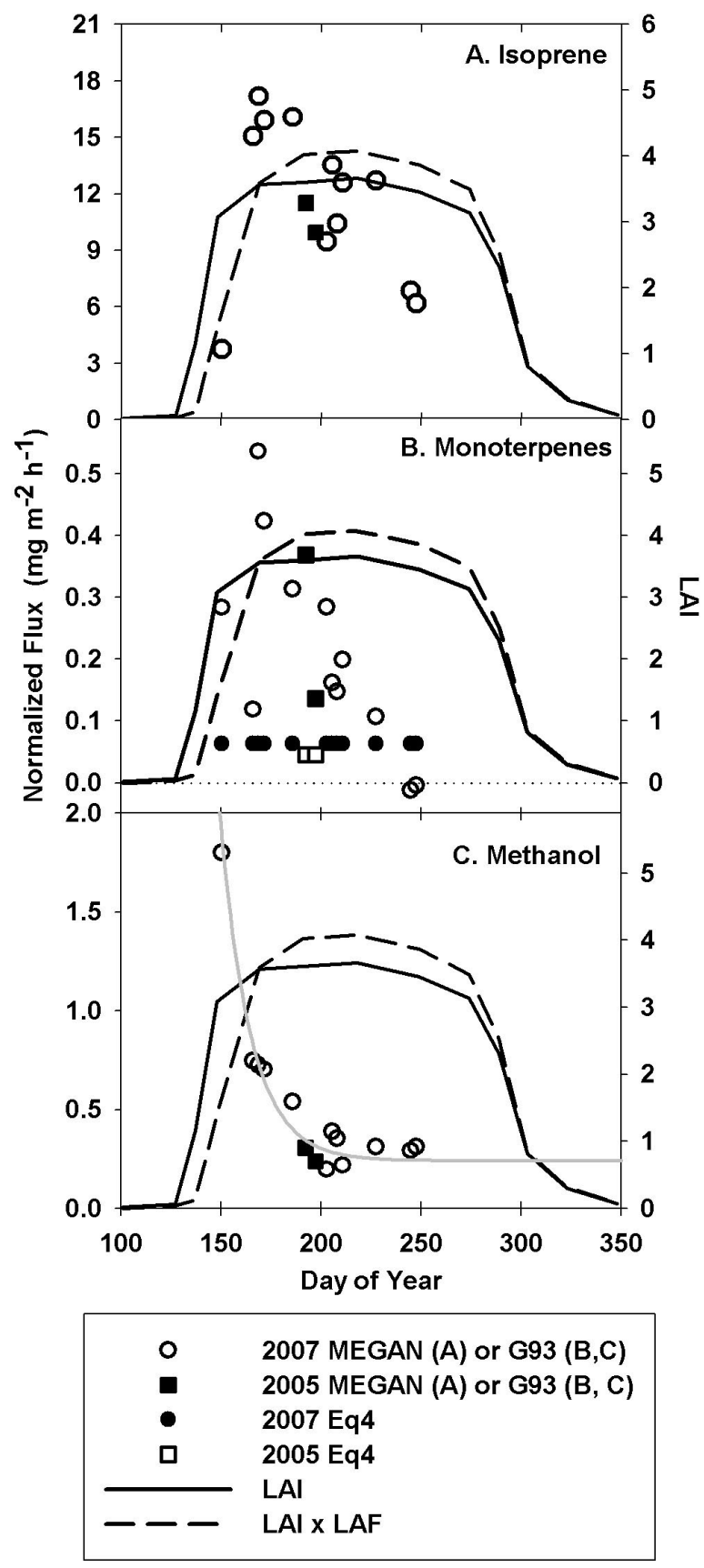

Fig. 8. Normalized emission rates for isoprene (A), monoterpenes (B), and methanol (C) over the course of the 2007 growing season. Also shown are the leaf area index and the product of the leaf area index and the leaf age factor (LAF). An exponential fit with a time constant of 15 days is also shown for methanol (grey line).

show, however, that isoprene emissions decrease in the fall well before LAI, falling to less than half their peak values by day 250 (7 September). Phenology data from Harvard Forest indicates that a small percentage (1-5\%) of oak leaves had begun to color by this time, though leaf drop did not occur for more than a month (O'Keefe, 2000).
The decrease in emissions in fall seen here is consistent with the observations of Goldstein et al. (1998), who reported fluxes decreasing to only ca. $10 \%$ of their peak summer values by day 250. Müller et al. (2008) used MEGAN, including a canopy environment model, to simulate the Goldstein et al. (1998) isoprene flux measurements. They were able to capture some seasonality by using the leaf age factor, though they also noted the tendency of the model to overpredict emissions before day 160 and after day 260. Müller et al. (2008) also noted model predictions of isoprene emissions were systematically low by ca. $35 \%$ compared to the Goldstein et al., (1998) measurements, most likely due to a lower standard emission factor in the MEGAN inventory than is representative of the Harvard Forest site.

In addition to the fall decrease, there is also some suggestion in the data of a larger early season peak in standard emission rate followed by a slow decline over the season that is not predicted by the product of LAI and leaf age factor. Additional data over subsequent seasons would be helpful in determining the representativeness of this behavior. Longer term measurements at a single location are desirable for assessing effects such as this with timescales of a season or longer and continuing measurements of BVOC fluxes from Harvard Forest are planned for the future to help address this question. There is also significant variability in the normalized emission rate during mid-summer, suggesting effects not accounted for in the model. This could be due in part to factors known to affect isoprene emissions but not included in the implementation used here, such as soil moisture.

\subsubsection{Monoterpenes}

In contrast to isoprene, which is not stored in the plant but is emitted immediately following production, monoterpenes can be emitted promptly or from stored pools. In general, prompt emissions reflect the controls on biosynthesis in the plant, and therefore typically exhibit dependence on both light and temperature, whereas emission from stored pools is regulated by the vapor pressure and hence depends on temperature alone (Laothawornkitkul et al., 2009). At the canopy scale, combinations of the two types of mechanisms are also possible if both types of emitters are present at a given site (Ortega et al., 2007). Though many observations of lightdependent monoterpene emissions from a variety of species have been made in Europe (Kesselmeier et al., 1996, 1997; Ciccioli et al., 1997; Kesselmeier and Staudt, 1999; Dindorf et al., 2006) and in tropical rain forests (Kuhn et al., 2002, 2004; Rinne et al., 2002; Karl et al., 2004), relatively few have been made in North America (Ortega et al., 2007). Instead, most of the studies in North America, which have been carried out mainly at coniferous forests, and have reported emissions depending only on temperature (Schade and Goldstein, 2001; Lee et al., 2005; Helmig et al., 2006; Kim et al., 2010). 
The standard functional form for describing temperature dependent emissions is that of Guenther et al. (1993):

$E=E_{\mathrm{S}} \times \exp \left[\beta\left(T-T_{\mathrm{S}}\right)\right]$

where $E$ is the temperature dependent emission rate, $E_{\mathrm{s}}$ is the standard emission rate, $T$ and $T_{\mathrm{s}}$ are the actual and standard $\left(30^{\circ} \mathrm{C}\right)$ temperatures, respectively, and $\beta$ is an empirical temperature response parameter. $E_{\mathrm{s}}$ was determined for the observed monoterpene fluxes using an exponential fit to $E$ vs. $T-T_{\mathrm{s}}$ with $\beta=0.10 \mathrm{~K}^{-1}(R=0.74$ and 0.44 for 2005 and 2007 model fits, respectively). For the time period shown in Fig. 3, the value of $E_{\mathrm{S}}$ determined from the best fit was $0.17 \mathrm{mg} \mathrm{m}^{-2} \mathrm{hr}^{-1}$. The resulting predicted emissions as a function of time are shown together with the observations in Fig. 3.

Similar to isoprene, the monoterpene emissions cycle has a large diel amplitude with the emissions decreasing to near zero at night. In addition, the peak monoterpene flux occurs at midday, not during the afternoon when the temperature is at its maximum. A comparison of the data with the model fit in Fig. 3 demonstrates that the temperature-dependent algorithm cannot capture either the nighttime minimum or the mid-day maximum emissions. The temperature-dependent algorithm also tends to peak later in the day than the observed maximum flux. This suggests that the monoterpene emissions from Harvard Forest depend not only on temperature, but also on light. Hence, the light- and temperaturedependent G93 algorithm normally used for isoprene was also applied to the monoterpenes (Kuhn et al., 2002, 2004; Ciccioli et al., 1997; Dindorf et al., 2006). In general, the agreement between the model prediction and the observations is much improved by including the light-dependent term. However, the model predicts no emissions during darkness, which leads to an underestimation of the fluxes measured at night, particularly for the 2005 data. The presence of small but non-zero nighttime fluxes implies that there may be both light-dependent and light-independent terms contributing to the monoterpene emissions. To constrain both terms, the nighttime (PPFD $<100 \mu \mathrm{mol} \mathrm{m}{ }^{-2} \mathrm{~s}^{-1}$ ) data for each season was first fit using Eq. (4). The fit was used to determine a single temperature-dependent emission term for each season, which was then subtracted from the total flux. The residual represents the light-dependent emission term. The standard light-dependent emission rate for each 2-3 day data interval was then obtained by fitting a regression of the residual fluxes against the modeled activity factor, in the same manner as for isoprene. Parameters for both terms, as well as the correlation coefficients between the modeled and measured emission rates are given in Table 3. The resulting modeled fluxes, which are the sum of the temperature dependent and temperature-independent terms, are shown together with the data in Fig. 3.

Because the fluxes measured in darkness were highly variable and exhibited a relatively weak temperature dependence, it was not possible to separately constrain the temperature dependent term for each 2-3 day interval. The uncertainty in the nighttime fluxes could be a result of the innaccuracy of the eddy covariance method under stagnant nighttime conditions; $u^{*}$ falls below the threshold value of $0.2 \mathrm{~m} \mathrm{~s}^{-1}$ for many of the nighttime data points. However, nighttime data points with $u^{*}$ values above $0.2 \mathrm{~m} \mathrm{~s}^{-1}$ also exhibit small and variable fluxes. It may be possible to better quantify the temperature-dependent term in the future by increasing the measurement precision (through reducing the mass cycle time or increasing the flux integration time) or by using alternate methods, such as a branch enclosure technique.

The observation of light-dependent monoterpene emissions at Harvard Forest is not unprecedented. Recently, Ortega et al. (2007) reported both temperature- and light- and temperature-dependent emissions in branch-level enclosure studies conducted in a mixed northern hardwood forest in Michigan. They observed light-dependent emissions from red oak (Quercus rubra), red maple (Acer rubrum), and paper birch (Betula papyrifera) (Ortega et al., 2007). The two former are the dominant tree species at the Harvard Forest site, so it is reasonable that similar functional dependencies on $T$ and PPFD would be observed.

The standard emission rates obtained by normalizing the data using the combined $T$-independent and $T$-dependent model in 2-3-day intervals are plotted as a function of day of the year in Fig. 8. Also included in the figure are the leaf area index and its product with the leaf age factor, as described for isoprene. The seasonal cycle observed for the monoterpene emissions after normalization for temperature and light conditions is quite similar to that of isoprene. Normalized emission rates for both peak in early summer (13-22 June) and then begin to decrease gradually through the summer, with light-dependent monoterpene emissions falling to approximately 0 by day 250 (7 September). The observed fluxes on this date represent about $20 \%$ of the peak summer value, and can be described using only the temperaturedependent term in the model. As was the case for isoprene the product of LAI and $\gamma_{\text {age }}$ does not adequately describe the decline in emissions at the end of the growing season.

The mean summertime (JJA) normalized light-dependent monoterpene emission rate was $0.25 \mathrm{mg} \mathrm{m}^{-2} \mathrm{hr}^{-1}$ in both 2005 and 2007, with a light-independent normalized emission rate of 0.05 and $0.06 \mathrm{mg} \mathrm{m}^{-2} \mathrm{hr}^{-1}$ for 2005 and 2007 , respectively. Although the normalization procedure used in this study is different, making direct comparisons difficult, these values are lower than standard emission rates observed above the canopy at a California ponderosa pine plantation (0.69-1.1 $\mathrm{mg} \mathrm{m}^{-2} \mathrm{hr}^{-1}$, Lee et al., 2005), a Scots pine forest in Finland (1.1-1.6 $\mathrm{mg} \mathrm{m}^{-2} \mathrm{hr}^{-1}$, Rinne et al., 2007) or a northern European deciduous forest $\left(0.65 \mathrm{mg} \mathrm{m}^{-2} \mathrm{hr}^{-1}\right.$, Spirig et al., 2005), but consistent with the species distribution at Harvard Forest. 
Table 4. Correlation coefficients between fluxes of individual species calculated for days 201 to 212 of 2007.

\begin{tabular}{lllllll}
\hline species & methanol & acetone & isoprene & $m / z=73$ & terpenes & $m / z=153$ \\
\hline methanol & 1 & & & & & \\
acetone & 0.37 & 1 & & & & \\
isoprene & 0.64 & 0.18 & 1 & & & \\
$m / z=73$ & 0.59 & 0.46 & 0.56 & 1 & & 1 \\
Terpenes & 0.33 & -0.02 & 0.72 & 0.39 & 1 & \\
$m / z=153$ & 0.15 & 0.007 & 0.23 & 0.15 & 0.18 & 1 \\
\hline
\end{tabular}

\subsection{Oxygenated VOCs}

The oxygenated VOCs methanol, acetone, and methyl ethyl ketone (MEK) typically exhibit peak fluxes around mid-day and minima at night (Fig. 5). As discussed in Sect. 3, negative fluxes are also observed for some species, especially during the predawn hours. The fluxes of these species are highly correlated with one another. Table 4 lists correlation coefficients for linear least squares fits between species for a subset of the 2007 data. The strongest correlations are between isoprene and monoterpenes, methanol and isoprene, and methanol and $m / z=73$ (MEK). Correlations with acetone are less strong, likely due to the frequent negative fluxes exhibited by it. This suggests that the emissions of monoterpenes, methanol, and perhaps $m / z=73$ respond to environmental factors in a similar manner to isoprene. Specifically, this may indicate light dependence of these compounds.

Short-chain alcohols and ketones, which are slightly soluble, exist partially in the aqueous phase inside the foliage. Because their vapor pressure is buffered by the aqueousphase concentration, emissions of these compounds are more sensitive to stomatal conductance than the highly volatile isoprenoids and terpenoids, which accumulate high internal partial pressures that compensate for reduced stomatal conductance (Niinemets and Reichstein, 2003a). Other factors that may be important in determining emission rates include the mechanism and rate of production in the plant, the stage of the plant growth cycle, temperature and light, water availability, damage or stress, and the atmospheric concentration of the compound (Seco et al., 2007). Some studies have also shown that these OVOCs can be emitted from soils and decaying plant matter as well as from live plants (Warneke et al., 1999; Schade and Goldstein, 2001; Schade and Custer, 2004) and there could be a soil contribution to canopy-scale flux measurements of these species. At present, there are no widely accepted models for predicting the emissions of these compounds. Nevertheless, several canopy scale studies have indicated that emissions of most OVOCs respond to temperature among other possible drivers (Schade and Goldstein, 2001; Karl et al., 2003, 2004, 2005). Some have also reported good correlations between OVOC fluxes and sensible heat fluxes (Karl et al., 2002). Assessing the relationship be- tween fluxes and these parameters is a reasonable first step in the absence of more detailed models.

The relatively long atmospheric lifetimes of most small OVOCs (several days for methanol and acetone) mean that they are unlikely to be oxidized between emission and escape from the canopy (Rinne et al., 2007). Advection from upwind anthropogenic sources can contribute to levels seen at the forest. In addition to biogenic and anthropogenic emissions, secondary production is also a major source of these compounds. Longer lifetimes and more diffuse sources lead to generally higher atmospheric concentrations for these species and less pronounced diel mixing ratio cycles than are observed for the isoprenoids.

\subsubsection{Methanol}

Studies have shown that methanol emissions depend strongly on stomatal conductance, as well as temperature and possibly PPFD, though these factors are in turn are interrelated, so it is difficult to deconvolve the relationships into independent terms (Macdonald and Fall, 1993; Nemecek Marshall et al., 1995; Harley et al., 2007). Ultimately, however, it is the methanol production rate within the plant, which in turn depends on temperature and growth rate, that determines emissions (Harley et al., 2007). The increase in methanol production due to pectin demethylation in rapidly growing young leaves is responsible for observations of higher methanol fluxes from plants in the spring (Fall and Benson, 1996; Fall, 2003; Karl et al., 2003). Huve et al. (2007) have shown that diurnal variations in growth rate lead to corresponding variations in methanol production, which can contribute to the diel emissions pattern. Niinemets and Reichstein (2003a, b) have developed a methanol emissions model based on physiological and physicochemical processes. However, the full model depends on a variety of leaf characteristics (Niinemets and Reichstein, 2003a, b), not all of which are known for all species. It is also necessary to predict the methanol production rate in the plant and the stomatal conductance as a function of temperature and light (Harley et al., 2007). Though progress is being made, there is not as yet a canopy-scale model that explicitly incorporates these processes.

Previous canopy-scale studies have used a variety of methods to describe the observed diurnally varying methanol 
emissions. Karl et al. (2003) and Schade and Goldstein (2001) fit their measurements with the standard temperaturedependent function (Eq. 4), though Schade and Goldstein (2001) noted that the fluxes were also correlated with light. Karl et al. (2002) compared their observations with linear functions of $w^{\prime} T^{\prime}$ (sensible heat) and $w^{\prime} q^{\prime}$ (latent heat), an exponential function of $T$, and two different functions of both $T$ (linear or exponential dependence) and PPFD (linear dependence), and found the best correlation between methanol emissions and $w^{\prime} T^{\prime}$. Folkers et al. (2008) evaluated two functions, each including a sum of temperaturedependent and light and temperature-dependent terms, both of which compared well with field observations.

To test the influence of light and temperature, the observed methanol fluxes were modeled with the standard exponential temperature dependence function (Eq. 4) and with the Guenther et al. (1993) (G93) algorithm. A linear function of the sensible heat flux was also tested and found to yield a low correlation coefficient $(R=0.42)$. The Eq. (4) and G93 model fits are compared to the measured fluxes in Fig. 3. The nighttime methanol emissions were near zero (mean dark flux of -0.007 and $0.002 \mathrm{mg} \mathrm{m}^{-2} \mathrm{hr}^{-1}$ in 2005 and 2007, respectively). Though there is some indication of a small temperature-dependent emission term during darkness, it was not sufficient to obtain a fit. In addition to the low nighttime values, the high correlation of the methanol fluxes with those of isoprene implies that the factors controlling methanol emissions are similar to those for isoprene. This evidence suggests that, under the conditions of these experiments, both temperature and light influence methanol emissions. Hence, although the correlation coefficients were similar ( $R=0.72$ for Eq. (4) and 0.80 for G93 for the 2007 data), the G93 algorithm was chosen for subsequent analysis.

The flux data was fit using the G93 algorithm for 23-day periods, yielding midsummer average normalized methanol emission rates of 0.27 and $0.34 \mathrm{mg} \mathrm{m}^{-2} \mathrm{hr}^{-1}$ in 2005 and 2007. This is consistent with the standard emission rates determined in canopy flux experiments by Karl et al. (2005) $\left(0.36-0.42 \mathrm{mg} \mathrm{m}^{-2} \mathrm{hr}^{-1}\right)$, but somewhat lower than those observed by Schade and Goldstein (2001) (2.87 mg m $\mathrm{m} \mathrm{hr}^{-1}$ ) and Karl et al. (2003) (0.87$\left.1.5 \mathrm{mg} \mathrm{m}^{-2} \mathrm{hr}^{-1}\right)$.

Several studies have reported morning pulses of methanol at sunrise (Nemecek Marshall et al., 1995; Huve et al., 2007; Harley et al., 2007; Niinemets and Reichstein, 2003a). Although there is some suggestion in the diel average cycle (Fig. 5) of a shoulder at this time, and a sharp rise is observed in some individual mornings (Fig. 3, Day 208), we did not observe a consistent pattern of morning bursts. Karl et al. $(2004,2005)$ reported canopy-scale methanol deposition in a tropical rain forest and a loblolly pine plantation in the southeastern US. Most episodes were observed at night. Both the diel average fluxes (Fig. 5) and the time series shown in Fig. 3 suggest that instances of uptake by the forest do occur, most commonly in the hours before sunrise, though they are relatively infrequent. These uptake events could be explained by uptake on surfaces wet with morning dew.

Standard emission rates are plotted as a function of day of the year in Fig. 8. The peak methanol emissions were observed in early spring, just as measurements began. Methanol mixing ratios and fluxes from this spring period are shown in Fig. 9. On day 149 and 150 (29 and 30 May), fluxes as high as $1.0 \mathrm{mg} \mathrm{m}^{-2} \mathrm{hr}^{-1}$, three times higher than the summer average, were observed. Mixing ratio measurements were started a week earlier than flux measurements (due to the instrument configuration), and these showed a peak methanol mixing ratio of nearly 25 ppbv on Day 145 . By the time the flux measurements started on day 149, the mixing ratio had decreased to $<10 \mathrm{ppbv}$. This suggests that the peak spring flux may have been even larger than that observed on days 149-150. A spring maximum is consistent with the theory that methanol is produced by pectin demethylation during cell wall elongation in growing leaves (Galbally and Kirstine, 2002; Nemecek Marshall et al., 1995; Fall and Benson, 1996) and with previous field observations Karl et al. (2003), although the magnitude of the enhancement is strikingly large. Normalized fluxes decreased roughly exponentially from the spring peak throughout the growing season with a time constant of about 15 days (Fig. 8), leveling off at ca. $0.25 \mathrm{mg} \mathrm{m}^{-2} \mathrm{hr}^{-1}$ in fall.

Niinemets and Reichtenstein $(2002,2003 a, b)$ described a detailed process-based model to predict methanol emissions from the internal methanol production rate, changes in the size of liquid and gas phase pools, and stomatal conductance. The spring emission surge observed in this study could provide an extremely valuable test of these models. At present, the models are tailored to leaf-level emissions and modifications would be necessary to apply them at the canopy scale (Harley et al., 2007). This deficiency highlights the need for ecosystem-scale models that capture the key attributes of the methanol production and emission mechanisms in plants.

\subsubsection{Acetone}

Enclosure experiments have found that acetone emissions are usually correlated with temperature (Schade and Goldstein, 2001; Cojocariu et al., 2004; Grabmer et al., 2006; Janson and de Serves, 2001), whereas any dependence on light appears to be weak (Cojocariu et al., 2004). Like methanol, acetone is a water soluble compound and hence might be expected to respond similarly to factors such as stomatal conductance. Yet, several studies have found no clear relationship between the two (Filella et al., 2009; Cojocariu et al., 2004). Filella et al. (2009) did observe bursts of acetone emission upon illumination under drought-stressed conditions. Winters et al. (2009) observed an inverse correlation between emission rate and ambient concentration, suggesting bidirectional exchange of acetone between the plant and the atmosphere. Consistent with these results, Cojocariu et al. (2004) observed acetone uptake in the dark, though the 

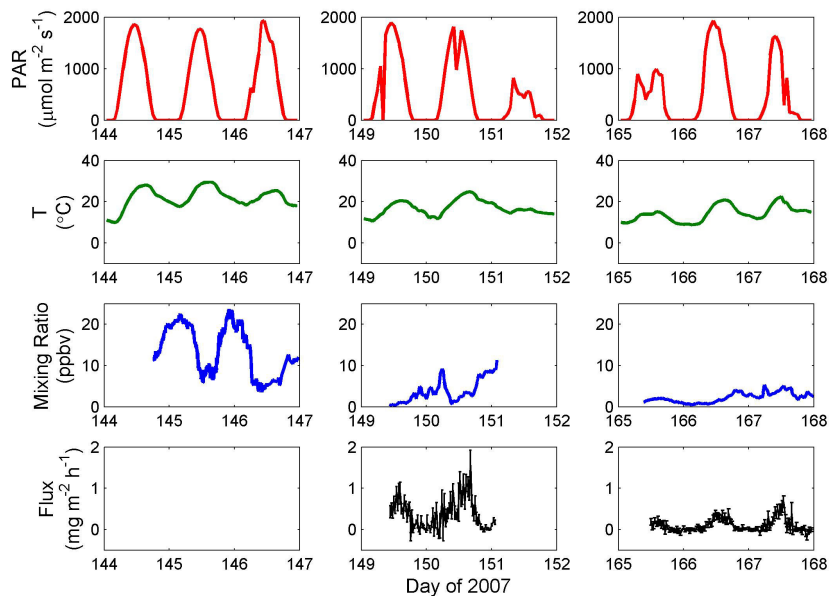

Fig. 9. Time series of methanol mixing ratio and flux during the spring of 2007. Also shown are PPFD and temperature.

authors note that the consumption pathway in the plant responsible for this acetone sink is unknown. Other factors observed to influence acetone emissions in some studies include wetting, humidity, stress, ozone and $\mathrm{CO}_{2}$ levels, and flooding (Warneke et al., 1999, 2002; Cojocariu et al., 2004, 2005; Holzinger et al., 2000; Filella et al., 2009; Kreuzwieser et al., 2002). In addition to direct emissions from leaves, there is evidence that acetone is emitted from decaying biomass and soils (Warneke et al., 2002; Schade and Goldstein, 2001). As in the case of methanol, there is not yet a standard processbased model for emissions of acetone.

To investigate the functional dependence of acetone emissions, data from each year was binned and averaged as a function of temperature as shown in Fig. 10. In general, the acetone flux increases at higher temperature in both years. However, as can be seen in both Figs. 5 and 10, the measured flux of acetone from the forest differed markedly between 2005 and 2007. As Fig. 5 shows, in 2007 acetone exhibited a diel cycle of positive fluxes from the forest during the afternoon hours, and negative fluxes in early morning. During the short observation period in 2005, deposition events were observed less frequently and the mid-day average flux was a factor of 5 higher than in 2007. Although the temperatures observed in 2005 were significantly higher, the temperature dependence in Fig. 10 shows that temperature alone does not account for the difference in the emission rates.

One possible explanation for the difference is an experimental artifact. Acetone is a polar, water soluble compound that, under certain circumstances, might be lost (or the highfrequency signal of which might be damped) during sampling. Experimental evidence suggests, however, that this is not the case. During zero air addition to the sample line, the acetone signal decays with a residence time of less than $10 \mathrm{~s}$, indicating wall interactions are minimal. Methanol is more soluble than acetone and is known to have more sig- nificant wall interactions, yet the fluxes of methanol in 2005 and 2007 are comparable, which argues against loss of highfrequency signals of soluble species due to damping in the sample lines. Finally, the amplitude of the observed diel average mixing ratio cycle of acetone is smaller in 2007 than in 2005 , in keeping with a smaller source of acetone from the forest. We conclude that the difference in the observed fluxes is real.

Though differences in micrometerological or physiological conditions other than temperature could have been factors, there were no marked differences in the leaf area index, PPFD, total precipitation, or relative humidity between the two years. There is, however, some indication that relative humidity could play a role. On average, under similar conditions of light and temperature, fluxes observed during periods of low relative humidity $(\mathrm{RH}<75 \%)$ are systematically higher than those observed during periods of high relative humidity. However, the trend is too small to be statistically significant or to account for the differences between 2005 and 2007. It is possible that the 2005 measurements were made during an unusually hot, dry period whereas those made in 2007 were confined to cooler, wetter conditions, giving rise to the apparent discrepancy. Though the reasons are unclear, it does appear that there was significantly more uptake during the observation period in 2007 than 2005, which would have resulted in a lower rate of escape from the canopy, even during periods of net positive flux. Additional measurements from subsequent seasons could help to resolve this issue.

Patterns of mid-day emission maxima and nighttime sinks such as the one seen in 2007 have been observed in other canopy-scale experiments (Karl et al., 2004, 2005). Karl et al. (2002), Goldstein and Schade (2000), Rinne et al. (2007), Schade and Goldstein (2001), and Karl et al. (2003) also report higher emissions during daylight, but no uptake at night. In some studies, however, no distinct diel cycle was found (Baker et al., 2001).

Equation (4) was used to quantify the relationship between the measured acetone fluxes and temperature, with the caveat that its usefulness is limited because it cannot reproduce observed features such as the episodes of acetone uptake. An exponential fit of the full data series using Eq. (4) yielded standard emission rates of $0.68 \mathrm{mg} \mathrm{m}^{-2} \mathrm{hr}^{-1}$ and $0.20 \mathrm{mg} \mathrm{m}^{-2} \mathrm{hr}^{-1}$ and $\beta$ values of $0.26 \mathrm{~K}^{-1}$ and $0.33 \mathrm{~K}^{-1}$ for the 2005 and 2007 data, respectively. The model prediction is shown together with the data for a short time window in Fig. 3. The standard emission rates are consistent with those determined in canopy flux experiments by Schade and Goldstein (2001) $\left(0.37 \mathrm{mg} \mathrm{m}^{-2} \mathrm{hr}^{-1}\right)$, Karl et al., (2003) (0.85-2.10 $\left.\mathrm{mg} \mathrm{m}^{-2} \mathrm{hr}^{-1}\right)$, and Karl et al. (2005) $\left(0.38 \mathrm{mg} \mathrm{m}^{-2} \mathrm{hr}^{-1}\right)$.

Additional plant-level studies are needed to better define the mechanism of acetone production and release. These could then be used to develop process-based models to be tested against data sets such as this one. 


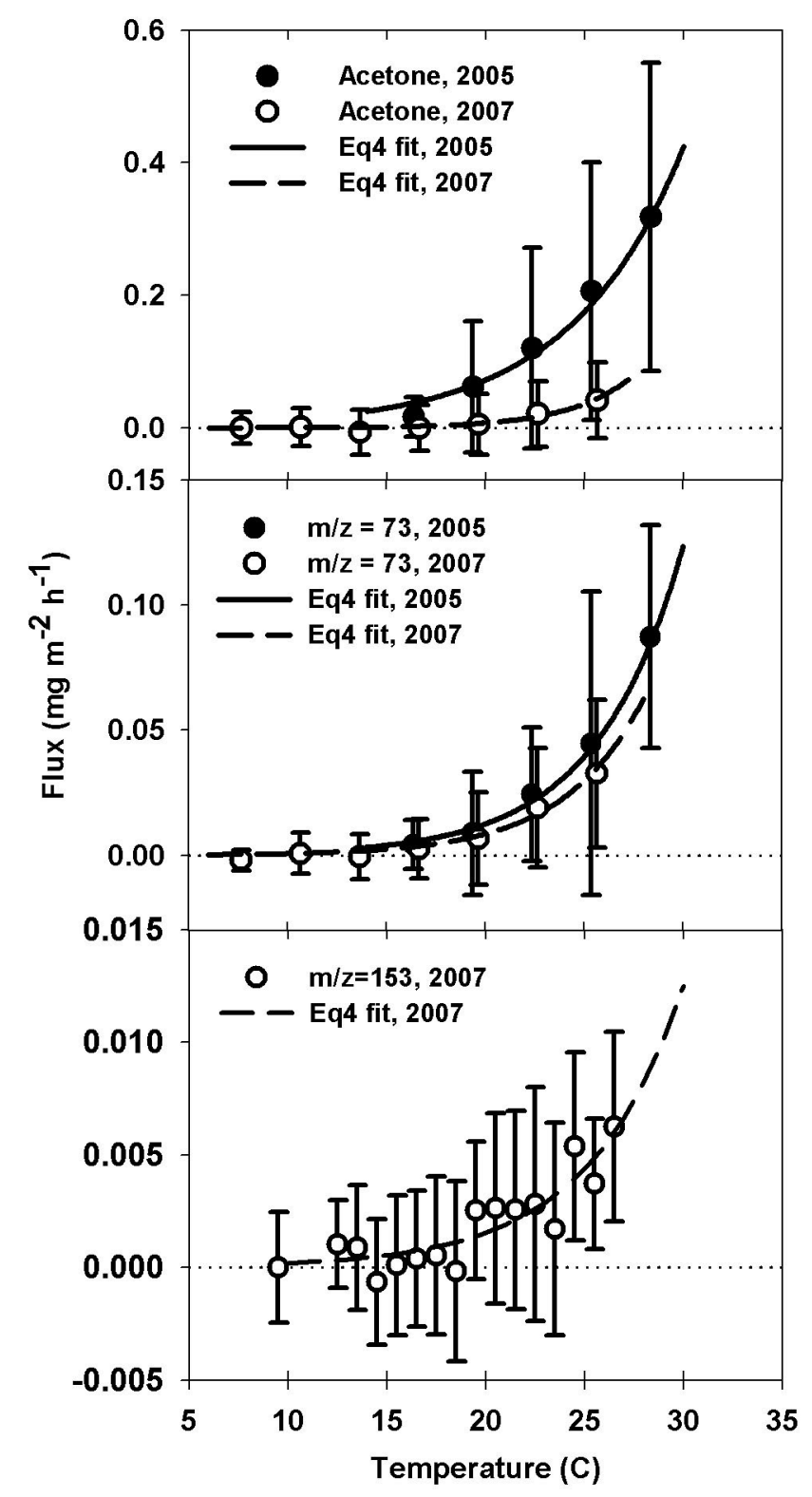

Fig. 10. Binned average fluxes of acetone, $\mathrm{m} / \mathrm{z}=73$, and $\mathrm{m} / \mathrm{z}=153$ during 2007 as a fucntion of temperature. For $m / z=153$, only the summer (JJA) of 2007 data is used. Error bars represent 1 standard deviation. Also shown are exponential fits to the data using Eq. (4) and the parameters for each species given in Table 3 .

\subsubsection{Methyl ethyl ketone}

Although the signal at $m / z=73$ has not been positively identified as MEK, the temporal patterns exhibited by this compound highly suggest that it is of biogenic origin. Very little is known about biogenic sources of MEK. de Gouw et al. (2003a) identified a compound observed in ambient air at $m / z=73$ as MEK using a GC-PTR-MS technique, and observed no interferences. It has also been observed via PTR-
MS by de Gouw et al. (1999), Karl et al. (2005), de Gouw et al. (2006), and Holzinger et al. (2000). Kirstine et al. (1998) detected emissions of MEK in enclosure studies over grassland using gas chromatography. There is little data on fluxes of this compound from forests.

The temperature dependence of the flux at $m / z=73$ (MEK) is shown in Fig. 10. Like acetone, the flux of this compound observed at each temperature was higher in 2005 than in 2007, though the difference is smaller and within the experimental uncertainty. Given the similarity in properties of these two compounds, it is reasonable to expect similar behavior. Both do show evidence of deposition episodes, but they are less pronounced for MEK than for acetone. This is reflected in the MEK diel average cycle, which reaches a minimum just before sunrise, but is not significantly below zero. Hence, this compound may escape the canopy more readily. The temperature dependence of the flux is determined by fitting to Eq. 4 in the same manner as for acetone, yielding $E_{\mathrm{S}}$ and $\beta$ values of $0.12 \mathrm{mg} \mathrm{m}^{-2} \mathrm{hr}^{-1}$ and $0.22 \mathrm{~K}^{-1}$ in 2005 and $0.10 \mathrm{mg} \mathrm{m}^{-2} \mathrm{hr}^{-1}$ and $0.25 \mathrm{~K}^{-1}$ in 2007. This suggests that the source of this compound from the canopy is about one half to one fifth that of acetone. The model prediction is shown together with the measured fluxes as a function of time in Fig. 3.

\subsection{4 $m / z=153$}

The signals at $m / z=153$ and 155 were chosen for flux determinations because they correspond to the molecular formulas of oxygenated terpenoids $\left(\mathrm{C}_{10} \mathrm{H}_{16} \mathrm{O}\right.$ and $\mathrm{C}_{10} \mathrm{H}_{18} \mathrm{O}$, respectively) and because diurnally varying signals were observed at these and several other mass-to-charge ratios during the summer of 2005. These signals could be due to primary emissions of oxygenated VOCs or to VOC oxidation products. Karl et al. (2005) suggested that, in addition to production in the gas phase, compounds of this type could be formed from reactions of ozone with leaf surfaces. Another possible candidate with protonated $m / z=153$ is methyl salicylate $\left(\mathrm{C}_{8} \mathrm{H}_{8} \mathrm{O}_{3}\right)$, a plant hormone signaling stress (Loreto and Schnitzler). Further studies using a method that provides additional structural information, such as GC-MS or PTRTOF-MS, are needed to identify this species. As shown in Fig. 7, a positive flux from the forest with a mid-day maximum was detected for $m / z=153$ during summer, but not during fall, consistent with a biogenic source. Fluxes were also computed for $m / z=155$ but no significant diel mean flux was detected.

Signals due to various BVOCs have been detected at $m / z=153$ in other studies. Tani et al. (2003) determined the proton transfer rate constant for camphor $(\mathrm{MW}=152)$ and found that it experiences minimal fragmentation in the PTR-MS. Kim et al. (2010) detect a signal at this $m / z$ in air above a pine forest, which they suggest could be due to camphor or other oxygenated terpenes with the same molecular formula $\left(\mathrm{C}_{10} \mathrm{H}_{16} \mathrm{O}\right)$. Using enclosure measurements, they 
determined mean daytime emission rates for this class of compounds of $0.4{\mu g^{-1}}^{-1}$ (leaf dry weight) $\mathrm{h}^{-1}$ in August and $0.15 \mu \mathrm{g} \mathrm{g}^{-1} \mathrm{~h}^{-1}$ in September. Emissions of camphor were also detected from Mediterranean species by Owen et al. (2001) and from a variety of mainly coniferous species at a series of locations in the US by Ortega et al. (2008) in branch enclosure experiments using GC methods. Although the compounds detected at $m / z=153$ in this study may not be camphor, the emission rate of $5 \mu \mathrm{g} \mathrm{m}^{-2} \mathrm{~h}^{-1}$, when normalized using an LAI of $3.6 \mathrm{~m}^{2} \mathrm{~m}^{-2}$ and a mean specific leaf weight for Harvard Forest of $62 \mathrm{~g} \mathrm{~m}^{-2}$ (Munger and Wofsy,

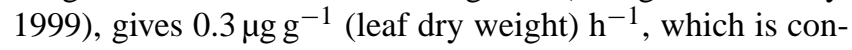
sistent with the flux reported by Kim et al. (2010) for this mass-to-charge ratio. The absence of detectable fluxes in fall is also consistent with Kim et al. (2010) who reported lower emission rates in September than in August. Karl et al. (2008) report ecosystem-scale fluxes of methyl salicylate from a walnut orchard in California. Emission rates as high as $0.25 \mathrm{mg} \mathrm{m}^{-2} \mathrm{hr}^{-1}$ were observed when the plants were under stress. These results suggest that methyl salicylate can have a significant canopy-scale flux and is also a viable candidate for detection by PTR-MS at this mass-to-charge ratio.

The $m / z=153$ fluxes from June, July, and August were binned in $1-{ }^{\circ} \mathrm{C}$ intervals and averaged; the result is shown in Fig. 10. The standard temperature dependent equation (Eq. 4) was used to fit the data, yielding values for $E_{\mathrm{s}}$ and $\beta$ of $0.012 \mathrm{mg} \mathrm{m}^{-2} \mathrm{hr}^{-1}$ and $0.21 \mathrm{~K}^{-1}$, respectively. However, due to the low signal and level of uncertainty, it was not possible to determine which type of function - whether dependent on temperature, light, a combination of these, or other factors - would best describe the emissions. More measurements and improved precision are necessary to further characterize the source of this species.

\section{Conclusions}

We have presented measurements of the fluxes isoprene, monoterpenes, and OVOCs methanol, and acetone from a mixed temperate forest over parts of two growing seasons. The quantities emitted are consistent with results from other locations, though Harvard Forest tends to produce more isoprene and somewhat less monoterpenes and acetone than are seen at other sites, many of which are coniferous forests in the western US and Europe. We have also reported data on compounds for which there are few existing measurements or which have only recently been detected, such as $m / z=73$ (MEK) and $m / z=153$. These results indicate that there are organic compounds emitted to the atmosphere that remain unidentified, particularly in forested regions.

Although many aspects of the observed emissions behavior are consistent with the current understanding of the biological and environmental factors governing BVOC emissions, and standard models do a good job of simulating the short-term variations, the results of this analysis points to several areas in need of improvement. These include the representation of the seasonal cycle for the isoprenoids as well as inclusion of both light- and temperature-dependent emissions for monoterpenes and possibly OVOCs. In general, the models have difficulty reproducing the amplitude of the diurnal cycle, including the midday peaks and nighttime lows near zero for most species. Inclusion of a full canopy environment model and leaf rather than air temperatures may help to reduce this discrepancy. The uncertainty associated with the nighttime flux measurements, particularly on nights when the boundary layer is very stable, makes determination of the functional dependence of the nighttime fluxes difficult. Nevertheless, the low nighttime fluxes observed in this study imply a light-dependent component of the emissions of many compounds reported here, particularly monoterpenes and methanol, perhaps due to the predominance of deciduous tree species at this site. Another contributing factor to the low nighttime fluxes is the observation of frequent episodes of deposition the oxygenated VOCs, particularly during times of high relative humidity, which are often encountered at night.

Models of OVOC emissions are at an earlier stage of development than those for the isoprenoids, and the processes they must describe are more complex. For example, in order to reproduce the observed negative fluxes, a canopy-scale model of acetone emissions would need to take into account not only processes within the plant, but also those taking place in the canopy after emission, where uptake can occur. By illuminating these processes and providing tests for model mechanisms, canopy-scale studies such as the one reported here form a key link in the model development process. More are needed to further refine emission algorithms so that accurate predictions of current and future BVOC emissions in a changing environment can be made and their contribution to oxidant and aerosol production can be assessed.

Acknowledgements. The authors thank S. Wofsy and the staff at Harvard Forest for their assistance with this project and C. Wiedinmyer and T. Karl for helpful discussions. Phenology data was provided by J. O'Keefe (Harvard Forest). This research was supported by an award from Research Corporation. Additional funding was provided by Amherst College and the Amherst College Chemistry Department. The EMS tower is a component of the Harvard Forest Long-term Ecological Research site, supported by NSF. The core micrometeorology measurements are supported in part by the Office of Science (BER), US Department of Energy grant DE-FG02-07ER64358, and through the Northeastern Regional Center of the National Institute for Climate Change Research (3452-HU-DOE-4157).

Edited by: J. Thornton 


\section{References}

Ammann, C., Spirig, C., Neftel, A., Steinbacher, M., Komenda, M., and Schaub, A.: Application of ptr-ms for measurements of biogenic voc in a deciduous forest, Int. J. Mass Spectrom., 239, 87-101, 2004.

Andreae, M. O., Artaxo, P., Brandão, C., Carswell, F. E., Ciccioli, P., da Costa, A. L., Culf, A. D., Esteves, J. L., Gash, J. H. C., Grace, J., Kabat, P., Lelieveld, J., Malhi, Y., Manzi, A. O., Meixner, F. X., Nobre, A. D., Nobre, C., Ruivo, M. d. L. P., SilvaDias, M. A., Stefani, P., Valentini, R., von Jouanne, J., and Waterloo, M. J.: Biogeochemical cycling of carbon, water, energy, trace gases, and aerosols in amazonia: The lba-eustach experiments, J. Geophys. Res., 107, 8066, doi:10.1029/2001jd000524, 2002.

Anicich, V. G.: An index of the literature for bimolecular gas phase cation-molecule reaction kinetics, JPL-Publication-03-19, 2003.

Atkinson, R.: Atmospheric chemistry of vocs and nox, Atmos. Environ., 34, 2063-2101, 2000.

Atkinson, R. and Arey, J.: Atmospheric chemistry of biogenic organic compounds, Acc. Chem. Res., 31, 574-583, 1998.

Atkinson, R., Baulch, D. L., Cox, R. A., Crowley, J. N., Hampson, R. F., Hynes, R. G., Jenkin, M. E., Rossi, M. J., Troe, J., and IUPAC Subcommittee: Evaluated kinetic and photochemical data for atmospheric chemistry: Volume II - gas phase reactions of organic species, Atmos. Chem. Phys., 6, 3625-4055, doi:10.5194/acp-6-3625-2006, 2006.

Baker, B., Guenther, A., Greenberg, J., and Fall, R.: Canopy level fluxes of 2-metyl-3-buten-2-ol, acetone and methanol by a portable relaxed eddy accumulation system, Environ. Sci. Technol., 35, 1701-1708, 2001.

Blake, R. S., Monks, P. S., and Ellis, A. M.: Protontransfer reaction mass spectrometry, Chem. Rev., 109, 861-896, doi:10.1021/cr800364q, 2009.

Bonn, B. and Moortgat, G. K.: Sesquiterpene ozonolysis: Origin of atmospheric new particle formation from biogenic hydrocarbons, Geophys. Res. Lett., 30(4), 1585, doi:10.1029/2003g1017000, 2003.

Bouvier-Brown, N. C., Goldstein, A. H., Gilman, J. B., Kuster, W. C., and de Gouw, J. A.: In-situ ambient quantification of monoterpenes, sesquiterpenes, and related oxygenated compounds during BEARPEX 2007: implications for gas- and particle-phase chemistry, Atmos. Chem. Phys., 9, 5505-5518, doi:10.5194/acp-9-5505-2009, 2009.

Chameides, W. L., Lindsay, R. W., Richardson, J., and Kang, C. S.: The role of biogenic hydrocarbons in urban photochemical smog: Atlanta as a case study, Science, 241, 1473-1475, 1988.

Ciccioli, P., Fabozzi, C., Brancaleoni, E., Cecinato, A., Frattoni, M., Loreto, F., Kesselmeier, J., Schafer, L., Bode, K., Torres, L., and Fugit, J. L.: Use of the isoprene algorithm for predicting the monoterpene emission from the mediterranean holm oak quercus ilex 1.: Performance and limits of this approach, J. Geophys. Res.-Atmos., 102, 23319-23328, 1997.

Ciccioli, P., Brancaleoni, E., Frattoni, M., Palo, V. D., Valentini, R., Tirone, G., Seufert, G., Bertin, N., Hansen, U., Csiky, O., Lenz, R., and Sharma, M.: Emission of reactive terpene compounds from orange orchards and their removal by within-canopy processes, J. Geophys. Res., 104, 8077-8094, 1999.

Cojocariu, C., Kreuzwieser, J., and Rennenberg, H.: Correlation of short-chained carbonyls emitted from picea abies with physio- logical and environmental parameters, New Phytol., 162, 717727, 2004.

Cojocariu, C., Escher, P., Haeberle, K.-H., Matyssek, R., Rennenberg, H., and Kreuzwieser, J.: The effect of ozone on the emission of carbonyls from leaves of adult fagus sylvatica, Plant, Cell Environ., 28, 603-611, 2005.

de Gouw, J. and Warneke, C.: Measurements of volatile organic compounds in the earth's atmosphere using proton-transferreaction mass spectrometry, Mass Spectrom. Rev., 26, 223-257, 2007.

de Gouw, J. A., Howard, C. J., Custer, T. G., and Fall, R.: Emissions of volatile organic compounds from cut grass and clover are enhanced during the drying process, Geophys. Res. Lett., 26, 811-814, 1999.

de Gouw, J., Warneke, C., Karl, T., Eerdekens, G., van der Veen, C., and Fall, R.: Sensitivity and specificity of atmospheric trace gas detection by proton-transfer-reaction mass spectrometry, Int. J. Mass Spectrom., 223-224, 365-382, 2003a.

de Gouw, J. A., Goldan, P. D., Warneke, C., Kuster, W. C., Roberts, J. M., Marchewka, M., Bertman, S. B., Pszenny, A. A. P., and Keene, W. C.: Validation of proton transfer reactionmass spectrometry (PTR-MS) measurements of gas-phase organic compounds in the atmosphere during the new england air quality study (NEAQS) in 2002, J. Geophys. Res., 108, 4682, doi:10.1029/2003JD003863, 2003b.

de Gouw, J. A., Warneke, C., Stohl, A., Wollny, A. G., Brock, C. A., Cooper, O. R., Holloway, J. S., Trainer, M., Fehsenfeld, F. C., Atlas, E. L., Donnelly, S. G., Stroud, V., and Lueb, A.: Volatile organic compounds composition of merged and aged forest fire plumes from alaska and western canada, J. Geophys. Res., 111, D10303, 10.1029/2005jd006175, 2006.

Demarcke, M., Amelynck, C., Schoon, N., Dhooghe, F., RimetzPlanchon, J., Van Langenhove, H., and Dewulf, J.: Laboratory studies in support of the detection of biogenic unsaturated alcohols by proton transfer reaction-mass spectrometry, Int. J. Mass Spectrom., 290, 14-21, 2010.

Di Carlo, P., Brune, W. H., Martinez, M., Harder, H., Lesher, R., Ren, X., Thornberry, T., Carroll, M. A., Young, V., Shepson, P. B., Riemer, D., Apel, E., and Campbell, C.: Missing oh reactivity in a forest: Evidence for unknown reactive biogenic vocs, Science, 304, 722-725, 2004.

Dindorf, T., Kuhn, U., Ganzeveld, L., Schebeske, G., Ciccioli, P., Holzke, C., Koble, R., Seufert, G., and Kesselmeier, J.: Significant light and temperature dependent monoterpene emissions from european beech (fagus sylvatica 1.) and their potential impact on the european volatile organic compound budget, J. Geophys. Res.-Atmos., 111, 15, D16305, 10.1029/2005jd006751, 2006.

Fall, R.: Abundant oxygenates in the atmosphere: A biochemical perspective, Chem. Rev., 103, 4941-4951, 2003.

Fall, R. and Benson, A. A.: Leaf methanol - the simplest natural product from plants, Trends Plant Sci., 1, 296-301, 1996.

Faloona, I., Tan, D., Brune, W., Hurst, J., Jr., D. B., Couch, T. L., Shepson, P., Apel, E., Riemer, D., Thornberry, T., Carroll, M. A., Sillman, S., Keeler, G. J., Sagady, J., Hooper, D., and Paterson, K.: Nighttime observations of anomalously high levels of hydroxyl radicals above a deciduous forest canopy, J. Geophys. Res., 106, 24315-24334, 2001.

Fehsenfeld, F., Calvert, J., Fall, R., Goldan, P., Guenther, A. B., He- 
witt, Nicholas, C., Lamb, B., Liu, S., Trainer, M., Westberg, H., and Zimmermann, P.: Emissions of volatile organic compounds from vegetation and the implications for atmospheric chemistry, Global Biogeochem. Cy., 6, 351-388, 1992.

Filella, I., Penuelas, J., and Seco, R.: Short-chained oxygenated voc emissions in pinus halepensis in response to changes in water availability, Acta Physiol. Plant., 31, 311-318, 10.1007/s11738008-0235-6, 2009.

Folkers, A., Huve, K., Ammann, C., Dindorf, T., Kesselmeier, J., Kleist, E., Kuhn, U., Uerlings, R., and Wildt, J.: Methanol emissions from deciduous tree species: Dependence on temperature and light intensity, Plant Biol., 10, 65-75, 2008.

Galbally, I. E., and Kirstine, W.: The production of methanol by flowering plants and the global cycle of methanol, J. Atmos. Chem., 43, 195-229, 2002.

Goldstein, A. H. and Galbally, I. E.: Known and unexplored organic constituents in the earth's atmosphere, Environ. Sci. Technol., 41, 1514-1521, 2007.

Goldstein, A. H. and Schade, G. W.: Quantifying biogenic and anthropogenic contributions to acetone mixing ratios in a rural environment, Atmos. Environ., 34, 4997-5006, 2000.

Goldstein, A. H., Goulden, M. L., Munger, J. W., Wofsy, S. C., and Geron, C. D.: Seasonal course of isoprene emissions from a midlatitude forest, J. Geophys. Res., 103, 31045-31056, 1998.

Goldstein, A. H., McKay, M., Kurpius, M. R., Schade, G. W., Lee, A., Holzinger, R., and Rasmussen, R. A.: Forest thinning experiment confirms ozone deposition to forest canopy is dominated by reaction with biogenic vocs, Geophys. Res. Lett., 31, L22106, doi:10.1029/2004GL021259, 2004.

Goulden, M. L., Munger, J. W., Fan, S. M., Daube, B. C., and Wofsy, S. C.: Measurements of carbon sequestration by longterm eddy covariance: Methods and a critical evaluation of accuracy, Global Change Biol., 2, 169-182, 1996.

Grabmer, W., Graus, M., Lindinger, C., Wisthaler, A., Rappengluck, B., Steinbrecher, R., and Hansel, A.: Disjunct eddy covariance measurements of monoterpene fluxes from a norway spruce forest using ptr-ms, Int. J. Mass Spectrom., 239, 111-115, 2004.

Grabmer, W., Kreuzwieser, J., Wisthaler, A., Cojocariu, C., Graus, M., Rennenberg, H., Steigner, D., Steinbrecher, R., and Hansel, A.: Voc emissions from norway spruce (picea abies 1. [karst]) twigs in the field-results of a dynamic enclosure study, Atmos. Environ., 40, 128-137, 2006.

Graus, M., Hansel, A., Wisthaler, A., Lindinger, C., Forkel, R., Hauff, K., Klauer, M., Pfichner, A., Rappenglück, B., Steigner, D., and Steinbrecher, R.: A relaxed-eddy-accumulation method for the measurement of isoprenoid canopy-fluxes using an online gas-chromatographic technique and ptr-ms simultaneously, Atmos. Environ., 40, 43-54, 2006.

Griffin, R. J., Cocker, D. R., III, Flagan, R. C., and Seinfeld, J. H.: Organic aerosol formation from the oxidation of biogenic hydrocarbons, J. Geophys. Res., 104, 3555-3567, 1999.

Grote, R. and Niinemets, U.: Modeling volatile isoprenoid emissions - a story with split ends, Plant Biol., 10, 8-28, doi:10.1055/s-2007-964975, 2008.

Guenther, A.: The contribution of reactive carbon emissions from vegetation to the carbon balance of terrestrial ecosystems, Chemosphere, 49, 837-844, 2002.

Guenther, A., Hewitt, C. N., Erickson, D., Fall, R., Geron, C.,
Graedel, T., Harley, P., Klinger, L., Lerdau, M., McKay, W. A., Pierce, T., Scholes, B., Steinbrecher, R., Tallamraju, R., Taylor, J., and Zimmerman, P.: A global model of natural volatile organic compound emissions, J. Geophys. Res., 100, 8873-8892, 1995.

Guenther, A., Geron, C., Pierce, T., Lamb, B., Harley, P., and Fall, R.: Natural emissions of non-methane volatile organic compounds, carbon monoxide, and oxides of nitrogen from north america, Atmos. Environ., 34, 2205-2230, 2000.

Guenther, A., Karl, T., Harley, P., Wiedinmyer, C., Palmer, P. I., and Geron, C.: Estimates of global terrestrial isoprene emissions using MEGAN (Model of Emissions of Gases and Aerosols from Nature), Atmos. Chem. Phys., 6, 3181-3210, doi:10.5194/acp-63181-2006, 2006.

Guenther, A. B., Zimmerman, P. R., Harley, P. C., Monson, R. K., and Fall, R.: Isoprene and monoterpene emission rate variability - model evaluations and sensitivity analyses, J. Geophys. Res.Atmos., 98, 12609-12617, 1993.

Hanson, D. R., Koppes, M., Stoffers, A., Harsdorf, R., and Edelen, K.: Proton transfer mass spectrometry at $11 \mathrm{hpa}$ with a circular glow discharge: Sensitivities and applications, Int. J. Mass Spectrom., 282, 28-37, 2009.

Harley, P., Fridd-Stroud, V., Greenberg, J., Guenther, A., and Vasconcellos, P.: Emission of 2-methyl-3-buten-2-ol by pines: A potentially large natural source of reactive carbon to the atmosphere, J. Geophys. Res., 103, 25479-25486, 1998.

Harley, P., Greenberg, J., Niinemets, ., and Guenther, A.: Environmental controls over methanol emission from leaves, Biogeosciences, 4, 1083-1099, doi:10.5194/bg-4-1083-2007, 2007.

Helmig, D., Ortega, J., Guenther, A., Herrick, J. D., and Geron, C.: Sesquiterpene emissions from loblolly pine and their potential contribution to biogenic aerosol formation in the southeastern us, Atmos. Environ., 40, 4150-4157, 2006.

Holzinger, R., Sandoval-Soto, L., Rottenberger, S., Crutzen, P. J., and Kesselmeier, J.: Emissions of volatile organic compounds from quercus ilex 1 . Measured by proton transfer reaction mass spectrometry under different environmental conditions, J. Geophys. Res.-Atmos., 105, 20573-20579, 2000.

Holzinger, R., Lee, A., Paw, K. T., and Goldstein, U. A. H.: Observations of oxidation products above a forest imply biogenic emissions of very reactive compounds, Atmos. Chem. Phys., 5, 67-75, doi:10.5194/acp-5-67-2005, 2005.

Holzinger, R., Lee, A., McKay, M., and Goldstein, A. H.: Seasonal variability of monoterpene emission factors for a ponderosa pine plantation in California, Atmos. Chem. Phys., 6, 1267-1274, doi:10.5194/acp-6-1267-2006, 2006.

Huve, K., Christ, M. M., Kleist, E., Uerlings, R., Niinemets, U., Walter, A., and Wildt, J.: Simultaneous growth and emission measurements demonstrate an interactive control of methanol release by leaf expansion and stomata, J. Exp. Bot., 58, 1783-1793, doi:10.1093/jxb/erm038, 2007.

Janson, R. and de Serves, C.: Acetone and monoterpene emissions from the boreal forest in northern europe, Atmos. Environ., 35, 4629-4637, 2001.

Kanakidou, M., Seinfeld, J. H., Pandis, S. N., Barnes, I., Dentener, F. J., Facchini, M. C., Van Dingenen, R., Ervens, B., Nenes, A., Nielsen, C. J., Swietlicki, E., Putaud, J. P., Balkanski, Y., Fuzzi, S., Horth, J., Moortgat, G. K., Winterhalter, R., Myhre, C. E. L., Tsigaridis, K., Vignati, E., Stephanou, E. G., and Wilson, 
J.: Organic aerosol and global climate modelling: a review, Atmos. Chem. Phys., 5, 1053-1123, doi:10.5194/acp-5-1053-2005, 2005.

Karl, T., Fall, R., Crutzen, P. J., Jordan, A., and Lindinger, W.: High concentrations of reactive biogenic vocs at a high altitude site in late autumn, Geophys. Res. Lett., 28, 507-510, doi:10.1029/2000g1012255, 2001a.

Karl, T., Guenther, A., Lindinger, C., Jordan, A., Fall, R., and W. Lindinger: Eddy covariance measurements of oxygenated volatile organic compound fluxes from crop harvesting using a redesigned proton-transfer-reaction mass spectrometer, J. Geophys. Res., 106, 24157-24167, 2001 b.

Karl, T., Spirig, C., Rinne, J., Stroud, C., Prevost, P., Greenberg, J., Fall, R., and Guenther, A.: Virtual disjunct eddy covariance measurements of organic compound fluxes from a subalpine forest using proton transfer reaction mass spectrometry, Atmos. Chem. Phys., 2, 279-291, 2002, http://www.atmos-chem-phys.net/2/279/2002/.

Karl, T., Guenther, A., Spirig, C., Hansel, A., and Fall, R.: Seasonal variation of biogenic voc emissions above a mixed hardwood forest in northern michigan, Geophys. Res. Lett., 30, 2186, doi:10.1029/2003GL018432, 2003.

Karl, T., Potosnak, M., Guenther, A., Clark, D., Walker, J., Herrick, J. D., and Geron, C.: Exchange processes of volatile organic compounds above a tropical rain forest: Implications for modeling tropospheric chemistry above dense vegetation, J. Geophys. Res.-Atmos., 109, D18306, doi:10.1029/2004JD004738, 2004.

Karl, T., Harley, P., Guenther, A., Rasmussen, R., Baker, B., Jardine, K., and Nemitz, E.: The bi-directional exchange of oxygenated VOCs between a loblolly pine (Pinus taeda) plantation and the atmosphere, Atmos. Chem. Phys., 5, 3015-3031, doi:10.5194/acp-5-3015-2005, 2005.

Karl, T., Guenther, A., Yokelson, R. J., Greenberg, J., Potosnak, M., Blake, D. R., and Artaxo, P.: The tropical forest and fire emissions experiment: Emission, chemistry, and transport of biogenic volatile organic compounds in the lower atmosphere over amazonia, J. Geophys. Res.-Atmos., 112, D18302, doi:10.1029/2007JD008539, 2007.

Karl, T., Guenther, A., Turnipseed, A., Patton, E. G., and Jardine, K.: Chemical sensing of plant stress at the ecosystem scale, Biogeosciences, 5, 1287-1294, doi:10.5194/bg-5-1287-2008, 2008.

Karl, T., Harley, P., Emmons, L., Thornton, B., Guenther, A., Basu, C., Turnipseed, A., and Jardine, K.: Efficient atmospheric cleansing of oxidized organic trace gases by vegetation, Science, 330, 816-819, doi:10.1126/science.1192534, 2010.

Kavouras, I. G., Mihalopoulos, N., and Stephanou, E. G.: Formation of atmospheric particles from organic acids produced by forests, Nature, 395, 683-686, 1998.

Keenan, T., Niinemets, U., Sabate, S., Gracia, C., and Penuelas, J.: Process based inventory of isoprenoid emissions from european forests: Model comparisons, current knowledge and uncertainties, Atmos. Chem. Phys., 9, 4053-4076, 2009,

http://www.atmos-chem-phys.net/9/4053/2009/.

Kesselmeier, J. and Staudt, M.: Biogenic volatile organic compounds (voc): An overview on emission, physiology and ecology, J. Atmos. Chem., 33, 23-88, 1999.

Kesselmeier, J., Schafer, L., Ciccioli, P., Brancaleoni, E., Cecinato, A., Frattoni, M., Foster, P., Jacob, V., Denis, J., Fugit, J. L., Dutaur, L., and Torres, L.: Emission of monoterpenes and isoprene from a mediterranean oak species quercus ilex 1 measured within the bema (biogenic emissions in the mediterranean area) project, Atmos. Environ., 30, 1841-1850, 1996.

Kesselmeier, J., Bode, K., Hofmann, U., Müller, H., Schäfer, L., Wolf, A., Ciccioli, P., Brancaleoni, E., Cecinato, A., Frattoni, M., Foster, P., Ferrari, C., Jacob, V., Fugit, J. L., Dutaur, L., Simon, V., and Torres, L.: Emission of short chained organic acids, aldehydes and monoterpenes from quercus ilex 1 . And pinus pinea 1 . In relation to physiological activities, carbon budget and emission algorithms, Atmos. Environ., 31, 119-133, 1997.

Kesselmeier, J., Ciccioli, P., Kuhn, U., Stefani, P., Biesenthal, T., Rottenberger, S., Wolf, A., Vitullo, M., Valentini, R., Nobre, A., Kabat, P., and Andreae, M. O.: Volatile organic compound emissions in relation to plant carbon fixation and the terrestrial carbon budget, Global Biogeochem. Cy., 16, 1126, 10.1029/2001gb001813, 2002.

Kim, S., Karl, T., Helmig, D., Daly, R., Rasmussen, R., and Guenther, A.: Measurement of atmospheric sesquiterpenes by proton transfer reaction-mass spectrometry (ptr-ms), Atmos. Meas. Tech., 2, 99-112, doi:10.5194/amt-2-99-2009, 2009.

Kim, S., Karl, T., Guenther, A., Tyndall, G., Orlando, J., Harley, P., Rasmussen, R., and Apel, E.: Emissions and ambient distributions of Biogenic Volatile Organic Compounds (BVOC) in a ponderosa pine ecosystem: interpretation of PTR-MS mass spectra, Atmos. Chem. Phys., 10, 1759-1771, doi:10.5194/acp-10-17592010, 2010.

Kirstine, W., Galbally, I., Ye, Y., and Hooper, M.: Emissions of volatile organic compounds (primarily oxygenated species) from pasture, J. Geophys. Res., 103, 10605-10619, 1998.

Kreuzwieser, J., Cojocariu, C., Juessen, V., and Rennenberg, H.: Elevated atmospheric $\mathrm{CO}_{2}$ causes seasonal changes in carbonyl emissions from quercus ilex, New Phytol., 154, 327-333, 2002.

Kuhn, U., Rottenberger, S., Biesenthal, T., Wolf, A., Schebeske, G., Ciccioli, P., Brancaleoni, E., Frattoni, M., Tavares, T. M., and Kesselmeier, J.: Isoprene and monoterpene emissions of amazonian tree species during the wet season: Direct and indirect investigations on controlling environmental functions, J. Geophys Res.-Atmos., 107, 8071, doi:10.1029/2001jd000978, 2002.

Kuhn, U., Rottenberger, S., Biesenthal, T., Wolf, A., Schebeske, G., Ciccioli, P., Brancaleoni, E., Frattoni, M., Tavares, T. M., and Kesselmeier, J.: Seasonal differences in isoprene and light-dependent monoterpene emission by amazonian tree species, Global Change Biol., 10, 663-682, 10.1111/j.15298817.2003.00771.x, 2004.

Kulmala, M., Suni, T., Lehtinen, K. E. J., Dal Maso, M., Boy, M., Reissell, A., Rannik, U., Aalto, P., Keronen, P., Hakola, H., Back, J. B., Hoffmann, T., Vesala, T., and Hari, P.: A new feedback mechanism linking forests, aerosols, and climate, Atmos. Chem. Phys., 4, 557-562, doi:10.5194/acp-4-557-2004, 2004.

Laothawornkitkul, J., Taylor, J. E., Paul, N. D., and Hewitt, C. N.: Biogenic volatile organic compounds in the earth system, New Phytol., 183, 27-51, 2009.

Lathiere, J., Hauglustaine, D. A., Friend, A. D., De NobletDucoudre, N., Viovy, N., and Folberth, G. A.: Impact of climate variability and land use changes on global biogenic volatile organic compound emissions, Atmos. Chem. Phys., 6, 2129-2146, doi:10.5194/acp-6-2129-2006, 2006.

Lee, A., Schade, G. W., Holzinger, R., and Goldstein, A. H.: A comparison of new measurements of total monoterpene flux with 
improved measurements of speciated monoterpene flux, Atmos. Chem. Phys., 5, 505-513, doi:10.5194/acp-5-505-2005, 2005.

Lindinger, W., Hansel, A., and Jordan, A.: On-line monitoring of volatile organic compounds atpptv levels by means of protontransfer-reaction mass spectrometry (ptr-ms) - medical applications, food control and environmental research, Int. J. Mass Spectrom. Ion Proc., 173, 191-241, 1998.

Loreto, F. and Schnitzler, J.-P.: Abiotic stresses and induced bvocs, Trends Plant Sci., 15, 154-166, 2010.

Macdonald, R. C. and Fall, R.: Detection of substantial emissions of methanol from plants to the atmosphere, Atmos. Environ., Part A, 27, 1709-1713, 1993.

McMillen, R. T.: An eddy-correlation technique with extended applicability to non-simple terrain, Boundary-Layer Meteorology, 43, 231-245, 1988.

Moody, J. L., Munger, J. W., Goldstein, A. H., Jacob, D. J., and Wofsy, S. C.: Harvard forest regional-scale air mass composition by patterns in atmospheric transport history (path), Journal of Geophysical Research, 103, 13181-13194, 1998.

Moore, K. E., Fitzjarrald, D. R., Sakai, R. K., Goulden, M. L., Munger, J. W., and Wofsy, S. C.: Seasonal variation in radiative and turbulent exchange at a deciduous forest in central massachusetts, J. Appl. Meteorol., 35, 122-134, doi:10.1175/15200450(1996)035;0122:SVIRAT i2.0.CO;2, 1996.

Muller, J. F., Stavrakou, T., Wallens, S., De Smedt, I., Van Roozendael, M., Potosnak, M. J., Rinne, J., Munger, B., Goldstein, A., and Guenther, A. B.: Global isoprene emissions estimated using megan, ecmwf analyses and a detailed canopy environment model, Atmos. Chem. Phys., 8, 1329-1341, doi:10.5194/acp-81329-2008, 2008.

Munger, J. W., Wofsy, S. C., Bakwin, P. S., Fan, S. M., Goulden, M. L., Daube, B. C., Goldstein, A. H., Moore, K. E., and Fitzjarrald, D. R.: Atmospheric deposition of reactive nitrogen oxides and ozone in a temperate deciduous forest and a subarctic woodland .1. Measurements and mechanisms, J. Geophys. Res.Atmos., 101, 12639-12657, 1996.

Munger, J. W., Fan, S.-M., Bakwin, P. S., Goulden, M. L., Goldstein, A. H., Colman, A. S., and Wofsy, S. C.: Regional budgets for nitrogen oxides from continental sources: Variations of rates for oxidation and deposition with season and distance from source regions, J. Geophys. Res., 103, 8355-8368, doi:10.1029/98jd00168, 1998.

Munger, W. and Wofsy, S.: Ems - biomass inventories: Hf069, in, Harvard Forest Data Archive, 1999.

Nemecek Marshall, M., Macdonald, R. C., Franzen, F. J., Wojciechowski, C. L., and Fall, R.: Methanol emission from leaves - enzymatic detection of gas-phase methanol and relation of methanol fluxes to stomatal conductance and leaf development, Plant Physiol., 108, 1359-1368, 1995.

Ng, N. L., Kroll, J. H., Keywood, M. D., Bahreini, R., Varutbangkul, V., Flagan, R. C., Seinfeld, J. H., Lee, A., and Goldstein, A. H.: Contribution of first- versus second-generation products to secondary organic aerosols formed in the oxidation of biogenic hydrocarbons, Environ. Sci. Technol., 40, 2283-2297, doi:10.1021/es052269u, 2006.

Niinemets, U. and Reichstein, M.: Controls on the emission of plant volatiles through stomata: Differential sensitivity of emission rates to stomatal closure explained, J. Geophys. Res.-Atmos., 108, 4208, doi:10.1029/2002jd002620, 2003a.
Niinemets, U. and Reichstein, M.: Controls on the emission of plant volatiles through stomata: A sensitivity analysis, J. Geophys. Res.-Atmos., 108, 4211, doi:10.1029/2002jd002626, 2003 b.

Niinemets, U., Reichstein, M., Staudt, M., Seufert, G., and Tenhunen, J. D.: Stomatal constraints may affect emission of oxygenated monoterpenoids from the foliage of pinus pinea, Plant Physiol., 130, 1371-1385, doi:10.1104/pp.009670, 2002.

Niinemets, U., Loreto, F., and Reichstein, M.: Physiological and physicochemical controls on foliar volatile organic compound emissions, Trends Plant Sci., 9, 180-186, doi:10.1016/j.tplants.2004.02.006, 2004.

O'Keefe, J.: Phenology of woody species: Hf003, in, Harvard Forest Data Archive, 2000.

Ortega, J., Helmig, D., Guenther, A., Harley, P., Pressley, S., and Vogel, C.: Flux estimates and oh reaction potential of reactive biogenic volatile organic compounds (bvocs) from a mixed northern hardwood forest, Atmos. Environ., 41, 5479-5495, 2007.

Ortega, J., Helmig, D., Daly, R. W., Tanner, D. M., Guenther, A. B., and Herrick, J. D.: Approaches for quantifying reactive and low-volatility biogenic organic compound emissions by vegetation enclosure techniques - part b: Applications, Chemosphere, 72, 365-380, doi:10.1016/j.chemosphere.2008.02.054, 2008.

Owen, S. M., Boissard, C., and Hewitt, C. N.: Volatile organic compounds (vocs) emitted from 40 mediterranean plant species: : Voc speciation and extrapolation to habitat scale, Atmos. Environ., 35, 5393-5409, 2001.

Papale, D., Reichstein, M., Aubinet, M., Canfora, E., Bernhofer, C., Kutsch, W., Longdoz, B., Rambal, S., Valentini, R., Vesala, T., and Yakir, D.: Towards a standardized processing of Net Ecosystem Exchange measured with eddy covariance technique: algorithms and uncertainty estimation, Biogeosciences, 3, 571-583, doi:10.5194/bg-3-571-2006, 2006.

Peñuelas, J. and Llusia, J.: Bvocs: Plant defense against climate warming?, Trends Plant Sci., 8, 105-109, doi:10.1016/s13601385(03)00008-6, 2003.

Peñuelas, J. and Staudt, M.: Bvocs and global change, Trends Plant Sci., 15, 133-144, 2010.

Pressley, S., Lamb, B., Westberg, H., Flaherty, J., Chen, J., and Vogel, C.: Long-term isoprene flux measurements above a northern hardwood forest, J. Geophys. Res., 110, D07301, doi:10.1029/2004JD005523, 2005.

Richardson, A. D. and O'Keefe, J. F.: Phenological differences between understory and overstory: A case study using the longterm harvard forest records, in: Phenology of ecosystem processes, edited by: Noormets, A., Springer Science \& Business Media, Heidelberg, Germany, 87-117, 2009.

Richardson, A. D., Hollinger, D. Y., Dail, D. B., Lee, J. T., Munger, J. W., and O'Keefe, J.: Influence of spring phenology on seasonal and annual carbon balance in two contrasting new england forests, Tree Physiol., 29, 321-331, doi:10.1093/treephys/tpn040, 2009.

Rinne, H. J. I., Guenther, A. B., Warneke, C., Gouw, J. A. d., and Luxembourg, S. L.: Disjunct eddy covariance technique for trace gas flux measurements, Geophys. Res. Lett., 28, 3139-3142, 2001.

Rinne, H. J. I., Guenther, A. B., Greenberg, J. P., and Harley, P. C.: Isoprene and monoterpene fluxes measured above amazonian rainforest and their dependence on light and temperature, Atmos. 
Environ., 36, 2421-2426, 2002.

Rinne, J., Taipale, R., Markkanen, T., Ruuskanen, T. M., Helln, H., Kajos, M. K., Vesala, T., and Kulmala, M.: Hydrocarbon fluxes above a Scots pine forest canopy: measurements and modeling, Atmos. Chem. Phys., 7, 3361-3372, doi:10.5194/acp-73361-2007, 2007.

Sakai, R. K., Fitzjarrald, D. R., and Moore, K. E.: Importance of low-frequency contributions to eddy fluxes observed over rough surfaces, J. Appl. Meteorol., 40, 2178-2192, doi:10.1175/15200450(2001)040;2178:IOLFCT i2.0.CO; 2, 2001.

Sander, R.: Compilation of henry's law constants for inorganic and organic species of potential importance in environmental chemistry (version 3): http://www.henrys-law.org, 1999.

Schade, G. W. and Custer, T. G.: Ovoc emissions from agricultural soil in northern germany during the 2003 european heat wave, Atmos. Environ., 38, 6105-6114, 2004.

Schade, G. W. and Goldstein, A. H.: Fluxes of oxygenated volatile organic compounds from a ponderosa pine plantation, J. Geophys. Res., 106, 3111-3123, 2001.

Seco, R., Penuelas, J., and Filella, I.: Short-chain oxygenated vocs: Emission and uptake by plants and atmospheric sources, sinks, and concentrations, Atmos. Environ., 41, 2477-2499, doi:10.1016/j.atmosenv.2006.11.029, 2007.

Sharkey, T. D., Wiberley, A. E., and Donohue, A. R.: Isoprene emission from plants: Why and how, Ann. Bot., 101, 5-18, 2008.

Smith, D. and Spanel, P.: Selected ion flow tube mass spectrometry (sift-ms) for on-line trace gas analysis, Mass Spectrom. Rev., 24, 661-700, 2005.

Spirig, C., Neftel, A., Ammann, C., Dommen, J., Grabmer, W., Thielmann, A., Schaub, A., Beauchamp, J., Wisthaler, A., and Hansel, A.: Eddy covariance flux measurements of biogenic VOCs during ECHO 2003 using proton transfer reaction mass spectrometry, Atmos. Chem. Phys., 5, 465-481, doi:10.5194/acp-5-465-2005, 2005.

Steinbacher, M., Dommen, J., Ammann, C., Spirig, C., Neftel, A., and Prevot, A. S. H.: Performance characteristics of a protontransfer-reaction mass spectrometer (ptr-ms) derived from laboratory and field measurements, Int. J. Mass Spectrom., 239, $117-$ 128, 2004.

$\mathrm{Su}, \mathrm{T}$. and Chesnavich, W. J.: Parametrization of the ion-polar molecule collision rate constant by trajectory calculations, The Journal of Chemical Physics, 76, 5183-5185, 1982.

Taipale, R., Ruuskanen, T. M., Rinne, J., Kajos, M. K., Hakola, H., Pohja, T., and Kulmala, M.: Technical Note: Quantitative long-term measurements of VOC concentrations by PTR-MS measurement, calibration, and volume mixing ratio calculation methods, Atmos. Chem. Phys., 8, 6681-6698, doi:10.5194/acp8-6681-2008, 2008.
Tani, A., Hayward, S., and Hewitt, C. N.: Measurement of monoterpenes and related compounds by proton transfer reaction-mass spectrometry (ptr-ms), Int. J. Mass Spectrom., 223-224, 561578, 2003.

Urbanski, S., Barford, C., Wofsy, S., Kucharik, C., Pyle, E., Budney, J., McKain, K., Fitzjarrald, D., Czikowsky, M., and Munger, J. W.: Factors controlling $\mathrm{CO}_{2}$ exchange on timescales from hourly to decadal at harvard forest, J. Geophys. Res.-Biogeosci., 112, 25, G02020, doi:10.1029/2006jg000293, 2007.

Vickers, D. and Mahrt, L.: Quality control and flux sampling problems for tower and aircraft data, J. Atmos. Ocean. Technol., 14, 512-526, 1997.

Warneke, C., Karl, T., Judmaier, H., Hansel, A., Jordan, A., and Lindinger, W.: Acetone, methanol, and other partially oxidized volatile organic emissions from dead plant matter by abiological processes: Significance for atmospheric hox chemistry, Global Biogeochem. Cy., 13, 9-17, 1999.

Warneke, C., Luxembourg, S. L., de Gouw, J. A., Rinne, H. J. I., Guenther, A. B., and Fall, R.: Disjunct eddy covariance measurements of oxygenated volatile organic compounds fluxes from an alfalfa field before and after cutting, J. Geophys. Res.-Atmos., 107, 4067 10.1029/2001JD000594 2002.

Warneke, C., Gouw, J. A. d., Kuster, W. C., Goldan, P. D., and Fall, R.: Validation of atmospheric voc measurements by proton-transfer-reaction mass spectrometry using a gaschromatographic preseparation method, Environ. Sci. Technol., 37, 2494-2501, 2003.

Winters, A. J., Adams, M. A., Bleby, T. M., Rennenberg, H., Steigner, D., Steinbrecher, R., and Kreuzwieser, J.: Emissions of isoprene, monoterpene and short-chained carbonyl compounds from eucalyptus spp. In southern australia, Atmos. Environ., 43, 3035-3043, doi:10.1016/j.atmosenv.2009.03.026, 2009.

Wofsy, S. C., Goulden, M. L., Munger, J. W., Fan, S.-M., Bakwin, P. S., Daube, B. C., Bassow, S. L., and Bazzaz, F. A.: Net exchange of $\mathrm{CO}_{2}$ in a midlatitude forest, Science, 260, 1314-1317, 1993.

Zhao, J. and Zhang, R.: Proton transfer reaction rate constants between hydronium ion $(\mathrm{H} 3 \mathrm{O}+)$ and volatile organic compounds, Atmos. Environ., 38, 2177-2185, 2004. 